\title{
UN TRAZADO REGULAR SUCESIVO: OVAL Y ENVOLVENTE. LA VILLA MEDIEVAL DE VITORIA
}

\author{
José Javier López de Ocáriz Alzola \\ Universidad de La Rioja
}

\begin{abstract}
RESUMEN: El entorno geográfico motivó en 1181 la elección de Gasteiz por el rey Sancho VI el Sabio de Navarra para fundar la villa de Vitoria como plaza de armas. Unas iglesias-bastiones y un entorno amurallado abrigaban tres calles adaptadas al óvalo perimetral de la colina. En cada mitad del siglo XIII se produjeron sendos ensanches de trazado simétrico, uno en el flanco oeste y otro en el este, cada uno con tres calles escalonadas envolviendo el recinto fundacional. Intervinieron los reyes castellanos Alfonso VIII y Alfonso X el Sabio. Nuevas funciones artesanales y comerciales le dieron prosperidad, aunque sin necesidad de rebasar las cercas medievales hasta el siglo XVIII. Gran parte del entramado urbano se conserva hoy, mostrando un ejemplo de planificación regular sucesiva: arriba el núcleo oval antiguo, y abajo un doble trazado envolvente.
\end{abstract}

Palabras clave: Ciudad medieval, tipología urbana, trazado regular, plaza de armas, muralla, puebla, Vitoria.

RÉSUMÉ: L'environnement géographique justifia la fondation de Vitoria en 1181, par le roi Sancho VI le Sage de Navarre, comme place d'armes. Des églises-forteresses et des remparts protégaient trois rues adaptées au contour ovale de la colline. À chaque moitié du XIllème siècle ont été bâtis deux quartiers neufs successifs, I'un vers l'ouest, l'autre vers l'est, dressés selon un même projet, en rangeant trois rues par degrés d'hauteur, qui entouraient de deux côtés l'enceinte supérieure ancienne. Les rois de Castille Alphonse VIII et Alphonse X le Sage y avaient établi tour à tour leur patronage. La ville prospérait, grâce à des métiers d'artisanat et de commerce, mais si calmement que le 
contour des remparts extérieurs n'a pas été franchi qu'au XVIIlème siècle. La plupart du réseau urbain médiéval reste encore intact, préservant un bon exemple de planification regulière successive: en haut le noyau ovale originel, en bas le double tracé enveloppant.

Mots-Clés: Ville médiévale, typologie urbaine, tracé régulier, cité, bastide, enceinte, Vitoria.

\section{La ciudad medieval}

Cada villa medieval, sea un núcleo de población grande o pequeño, puede ser admirada como monumento, restaurada y visitada, pero no debemos olvidar que constituye un rico documento histórico, con muchas vertientes de aproximación. Allí puede palparse el latido humano que perdura. Desde la arqueología, la historia política, económica o social, desde las aportaciones a la evolución artística, a las corrientes de pensamiento, religiosas, cultas y populares, o desde el tejido urbano, podemos abordarla como una fuente inagotable de descubrimientos y nuevas perspectivas ${ }^{1}$.

Al describir estas ciudades, uno de los temas más debatidos afecta a la tipología y, en ciertos casos, se ha centrado en la definición de unos cuantos tipos de clasificación, tratando de agruparlas, por morfología y funciones, dentro de una serie de modelos tipológicos. Un ejemplo tradicional de esta tendencia, hace referencia en Francia a las bastides ${ }^{2}$, fenómeno ampliamente estudiado y que presenta rasgos morfológicos e históricos convergentes. Paralelamente se intentan plasmar nuevos tipos, algo más discutibles, como las Ilamadas circulades organizadas en círculos concéntricos para su defensa. La bibliografía sobre este campo es ya muy amplia, tanto a nivel global como local ${ }^{3}$.

1. PIRENNE, Henri, Las ciudades de la Edad Media, Madrid, Alianza, 1972, (Paris, P.U.F., 1971), p.138: ... la ciudad medieval, tal y como aparece a partir del siglo XII, es una comuna que, al abrigo de un recinto fortificado, vive del comercio y de la industria y disfruta de un derecho, de una administración y de una jurisprudencia excepcionales, que la convierten en una personalidad colectiva privilegiada.

2. Se han Ilegado a clasificar como bastides una larguísima lista de casi 500 poblaciones en la mitad meridional de Francia, fundadas entre 1220 y 1370 . En otros territorios también ocurre un fenómeno similar.

3. Una muy útil recopilación bibliográfica de las fuentes escritas sobre el tema del urbanismo medieval en Álava y Vizcaya, en: DÍAZ DE DURANA, José Ramón, «El fenómeno urbano medieval en Álava y Vizcaya», en: SOLÓRZANO TELECHEA, Jesús Ángel; ARIZAGA BOLUMBURU, Beatriz (dir.), El fenómeno urbano medieval entre el Cantábrico y el Duero. Revisión historiográfica y propuestas de estudio, Santander, Micromegas 2, 2002. Ver su « Apéndice II : Fuentes publicadas. Clásicos». Monografias», pp. 74-87. También merece la atención el "Apéndice III : Planos 
Los estudios sobre la morfología de la ciudad medieval han insistido durante el último medio siglo en la pluralidad tipológica, dada la variedad de circunstancias geográficas y de procesos históricos. En tal sentido puede secundarse la opinión de Leonardo Benevolo: Estas ciudades tienen todas las formas posibles. Los estudiosos han intentado clasificarlas en varios tipos: lineales, circulares, radiocéntricas, escaqueadas, etc., pero no se ha logrado encontrar una causa constante por la cual se elige un tipo de ciudad y no otro. Toda ciudad es considerada como un caso especial, lo mismo cuando se ha desarrollado por una cadena de causas sucesivas, como cuando ha sido diseñada en una sola decisión inicial. No se acepta ninguna regla general, sino que se tienen en cuenta las infinitas circunstancias: la naturaleza del terreno, la tradición local, las sugestiones exóticas, el simbolismo sagrado y profano. Cada una de estas motivaciones puede ser determinante ${ }^{4}$.

Para situar la problemática, recogeremos algunas opiniones características sobre la ciudad medieval europea: El mundo medieval es esencialmente rural, pero la imagen de lugar más prestigiosa es la imagen de la ciudad, centro de poder, de riqueza, centro religioso, protegido dentro de las murallas y que ejerce una fascinación que a menudo domina y aplasta al campo, poblado de patanes, por villanos explotados y menospreciados. La ciudad también tiende al cielo por la verticalidad de las torres de las iglesias, los monumentos comunales y los palacios de los poderosos y los ricos. Se eleva hacia Dios con ese movimiento que obedece a la orientación preferida del espacio en la Edad Media: de abajo arriba ${ }^{5}$.

Como precedente de este mundo urbano que renace, la civilización clásica y en particular Roma, había proporcionado modelos y definiciones de ciudad. Recordamos en especial a Vitruvio que, pensando en los edificios públicos, recomienda tres cualidades: firmitas (solidez o durabilidad), utilitas (utilidad), venustas (belleza) $)^{6}$.

Tenemos presente las concisas precisiones en el siglo $\mathrm{V}$ de San Agustín de Hipona: non muri, sed mentes (no los muros sino las personas), o en el VII, de San Isidoro de Sevilla que parece citarle en sus Etimologías: La ciudad es una multitud de hombres vinculados con el lazo de la afinidad. Ciertamente la urbe se compone de murallas, pero la ciudad no consiste en las piedras, sino en los

\footnotetext{
y Mapas », pp. 88-109. Otros artículos de la misma publicación son muy recomendables para una puesta al día en el tema.

4. BENEVOLO, Leonardo, Diseño de la ciudad - 3. El arte y la ciudad medieval, Barcelona, G.Gili, 1981, 3ª ed. (G.Laterza, Roma-Bari, 1977), p.177.

5. LE GOFF, Jacques, Una Edad Media en imágenes, Barcelona, Paidós, 2009 (Paris, éd. Hazan, 2000), p. 39.

6. VITRUVIO, Marco Lucio, Los diez libros de arquitectura, Libro I, cap. III, (ed. Iberia, Barcelona, 1977), p.17.
} 
habitantes ${ }^{7}$. Pero ipor qué surgieron y se prodigaron de manera tan espectacular en los siglos finales de la Edad Media las ciudades, grandes o pequeñas, cubriendo los valles, organizando el espacio, y retornando a aquel olvidado urbanismo romano ${ }^{8}$ ?

Mucho se ha escrito sobre la villa o ciudad medieval como espacio de libertad, recordando la tan repetida frase: Stadtluft macht frei nach jahr und tag (EI aire de la ciudad hace libre tras un año y un día). Sirven como referente las palabras del historiador belga Henri Pirenne: Burgués y hombre libre se han convertido en términos sinónimos. La libertad es en la Edad Media un atributo tan inseparable de la condición de habitante de una ciudad como lo es, en nuestros días, de la de ciudadano de un Estado. Con la libertad personal va unida, en la ciudad, la libertad territorial. (...) la tierra, en la ciudad, cambia de naturaleza: se ha convertido en solar edificable. Se cubre rápidamente de casas apiñadas unas con otras y que aumentan su valor a medida que se multiplican ${ }^{9}$.

Esta visión optimista de la ciudad contrasta con algunos planteamientos muy realistas, que no dudan en utilizar calificativos irónicos, como Robert Fossier en un apartado que titula: La " auténtica » Edad Media ... radica también en que se funda en lo " innoble », la herramienta, el chamizo, la piedra de construcción, el esqueleto, y no en las guerras de los reyes y la santidad de los obispos..., o mordaces, como Georges Jehel, según el cual, hacia finales del siglo XII los habitantes de las ciudades se caracterizan por cierto estado de ánimo: el orgullo de los nobles, la bestialidad de los patanes y la avaricia de los burgueses ${ }^{10}$.

7. ISIDORO DE SEVILLA, Etymologiae, Liber XV, "De civitatibus": Civitas est hominum multitudo societatis vinculo adunata, dicta a civibus, id est ab ipsis incolis urbis (...). Nam urbs ipsa moenia sunt, civitas autem non saxa, sed habitatores vocantur. Ver también: DE SETA, Cesare, "Las murallas, símbolo de la ciudad", en La ciudad y las murallas, Madrid, 1991, pp.21-66.

8. MONSALVO ANTÓN, José María, Las ciudades europeas del medievo, Madrid, Síntesis, 1997, p. 95-96: La ciudad medieval despegó y se configuró como tal en los siglos de crecimiento económico, período que se extiende entre los siglos X y XIII. Y añade, citando a POUNDS, N., Historia económica de la Europa Medieval, Barcelona, de 1981: Al principio del ciclo expansivo apenas un centenar de núcleos podrían llamarse ciudades; al final varios miles podrían ya ser definidos como ciudades, cuando menos unos 2000 núcleos que funcionaban como centros de comercio regional y de concentración de artesanos. Prosigue en pp.97-98: ¿Qué impulsó el auge de las ciudades? Ciertamente, cada ciudad medieval tiene su historia particular, por lo que es difícil ofrecer respuestas idénticas. Los interrogantes históricos entonces se orientan en una doble dirección: conocer los factores concretos que convirtieron a una ciudad medieval en lo que fue; y determinar si, aparte de esto, hubo alguna causa común o general que explique el despertar urbano. Al final concluye en p.104: .... a partir de cierto momento, la ciudad es protagonista de la historia europea. Fossier señala que hasta el año 1200, la ciudad era un "cuerpo extraño", una especie de quiste, de malformación en la sociedad medieval.

9. PIRENNE, Henri, Las ciudades de la Edad Media, p.127.

10. FOSSIER, Robert, La Edad Media. 2. El despertar de Europa 950-1250, Barcelona, ed. Crítica, 1988 (Paris, éd. A.Colin, 1982), p.10. JEHEL, Georges; RACINET, Philippe, La Ciudad Medieval. Del Occidente cristiano al Oriente musulmán (siglo V- XV), Barcelona, Omega, 1999, 
Partiendo de su entorno, asistiremos a las circunstancias del nacimiento, ya avanzado el siglo XII, de Vitoria, una población renovada en su status, metamorfoseando la pujante aldea de Gasteiz. También evocaremos su implantación en un espacio público, evocando la fisonomía de sus murallas, puertas, iglesias y bastiones, tanto en la primera fase, encaramada al recinto superior, como en el desbordamiento sucesivo por ambas laderas ${ }^{11}$.

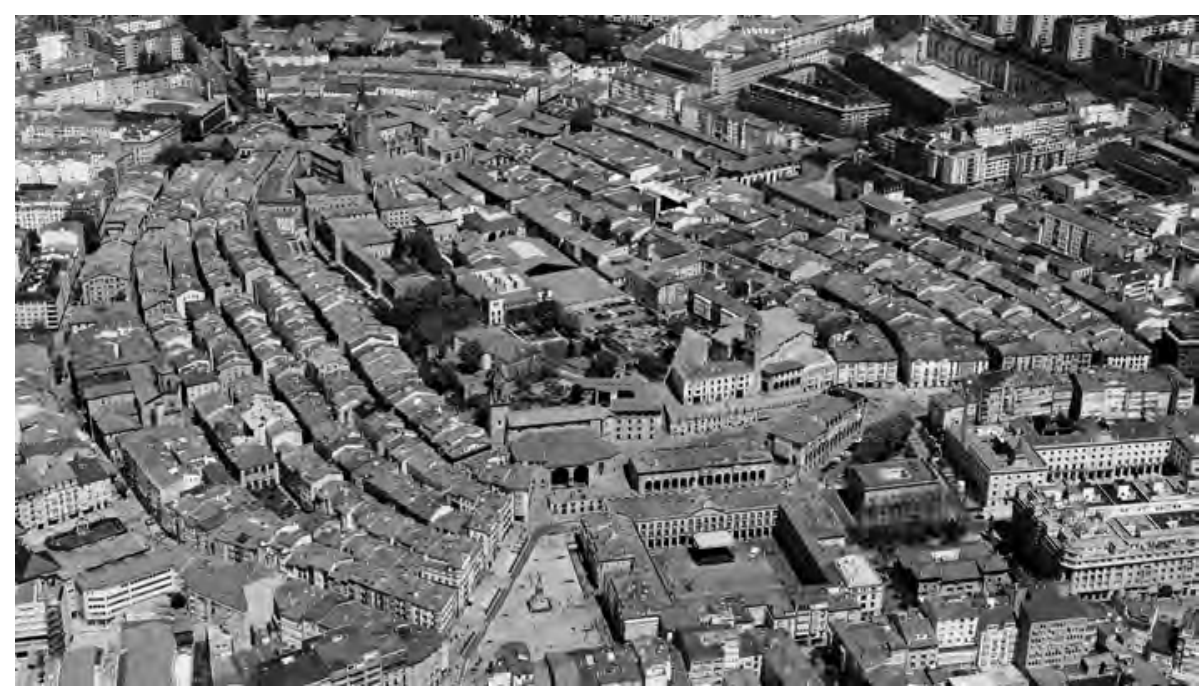

Figura 1: Vista aérea del Centro Histórico de Vitoria desde el sur. FOAT.

\section{Emplazamiento y situación}

El emplazamiento de Vitoria en medio de Alava fue ya magistralmente descrito en 1528 por el veneciano Navaggiero: una gran llanura rodeada de montañas como un anfiteatro, en cuyo centro está Vitoria, situada en un collado ${ }^{12}$, y desde ella se ven innumerables aldeas, según le dijeron, tantas como días tiene

p.309. MONSALVO ANTÓN, Las ciudades europeas, p. 14-15: En Inglaterra un prestigioso historiador como Postan ha llegado a afirmar que las ciudades europeas medievales eran islas "no feudales en un mar feudal».

11. LÓPEZ DE OCÁRIZ ALZOLA, José Javier, "Historia de Vitoria medieval y su topografía urbana", en Construcción de la ciudad. II Encuentro hispano-cubano de Arquitectura y Urbanismo, La Habana, 2009, pp.132-164.

12. SANTOYO, Julio César, Viajeros por Álava. Siglos XV al XVIII, Vitoria, 1972, pp.39-42. 
el año. Disculpando la exageración, al menos queda patente la impresión que producían la pequeñez y dispersión de los innumerables núcleos, algo que aún sigue asombrando al visitante. Por otro lado, conviene ya destacar que el emplazamiento concreto de la población y las características de su entorno, fueron determinantes para su desarrollo urbano.

Nos hallamos al norte de la Península Ibérica, entre el río Ebro, a unos 30 km por el sur y el mar Cantábrico, a 60 km por el norte. La disposición geográfica de este entorno prepirenaico responde a una cuenca fluvial, la del río Zadorra, y el aspecto es de un gran valle abierto, con un espacio relativamente Ilano como una cubeta de unos $20 \mathrm{~km}$ de diámetro, en donde se puede ubicar a Vitoria, en el centro de la parte occidental de la Llanada. Prosiguiendo hacia el este, tras las pequeñas elevaciones de Estíbaliz y Argómaniz, el llano permanece, y es Salvatierra quien centra la prolongación de la cuenca del Zadorra hacia su cabecera, en la Llanada oriental, donde el valle se va cerrando frente al corredor de la Burunda navarra. Así, entre ambos espacios, el conjunto de la comarca denominada Llanada alavesa comprende $785 \mathrm{~km}^{2}$.

El río Zadorra cruza la Llanada de este a oeste, doblándose finalmente hacia el sur para alcanzar al río Ebro, tras $85 \mathrm{~km}$ de recorrido. Poco antes del giro, queda su orilla a poco más de $2 \mathrm{~km}$ al norte de la villa antigua, aunque hoy la expansión urbana ha alcanzado y desbordado sus riberas. La inclinación del terreno hace derivar, desde los montes de Vitoria, una serie de arroyos que descienden hacia el Zadorra. Destacan dos riachuelos que discurren paralelos de norte a sur, dejando en medio de ellos, a un kilómetro de distancia de cada uno, la colina fundacional. El del levante es conocido por Errekatxiki (río pequeño) recordando su reducido flujo estival, con las aguas que bajan de Mendiola, pero que llegaba a tener el suficiente caudal como para alimentar algunos molinos, de los que también se conserva cerca de la campa de Olárizu el topónimo Rotazarra (molino viejo), a dos $\mathrm{km}$ al sur de la colina, y también en él consta la existencia de molinos mucho más cerca, a menos de un km por el este de la villa.

Cuando ya estaba poblado el este de la villa, se practicó una canalización de este Errekatxiki desde la zona donde ahora está el puente del polvorín viejo, pasando por el trazado actual de la calle de Los Herrán y el Artium, para alcanzar el borde oriental de la colina. Por el poniente es el arroyo Avendaño quien bordea la aldea de su mismo nombre, de la que perdura la ermita de San Martín, con restos de su estructura románica y pinturas góticas. A este arroyo Avendaño, poco antes de desaguar en el Río Zadorra, llega como afluente el Zapardiel, que adquiere protagonismo, pese a tratarse de un cauce menor, por cruzar justo al pie de la colina fundacional. Entre el Zapardiel por occidente y la canalización por levante, se llegó a perfilar un foso parcial que mejoraba el planteamiento defensivo.

La colina de la que hablamos está básicamente formada por margas calizas y materiales carbonatados del Cretácico Superior, y es lo que se conoce como un cerro testigo de la erosión de una cuenca, ocupada en buen parte por 
depósitos aluviales cuaternarios. Es una elevación que alcanza casi los 550 m sobre el nivel del mar, destacando entre 25 y 30 m sobre su base, y por ello sobresale como lugar eminente en la margen meridional del río Zadorra, de entre los suaves declives que descienden de los montes de Vitoria.

La colina es una franja alargada, que mide unos $400 \mathrm{~m}$ en sentido N-S, y se estrecha en el E-W, donde apenas Ilega a sobrepasar los 150 m. No son simétricas las laderas de la colina, acusándose unas pendientes bruscas en sus extremos norte y sur, y un fuerte desnivel en el costado occidental. La vertiente de levante es más suave y sobre todo se advierte una rampa natural de más cómodo acceso en el ángulo sudeste. La plataforma superior, relativamente Ilana, alcanza más de 4 Hectáreas de superficie, y constituye una atalaya natural para controlar un cruce de caminos, atestiguados a sus pies desde épocas antiguas.

El acceso habitual a la colina es por el ángulo sudeste, si nos guiamos por el desnivel más suave del terreno, que ahí se muestra como una rampa natural de cómoda subida. Se puede ascender en 400 metros de recorrido por la cuesta actual del Portal del Rey, San Francisco y San Vicente, hacia el frente sur de Villasuso en San Vicente, con una larga rampa del $4 \%$, mientras que si se intenta directamente desde el sur, el nivel queda plano hasta el mismo pie y de ahí se plantea como un frente muy abrupto. Ningún otro punto del entorno permite un acceso tan cómodo, y si se intenta el ascenso desde el extremo norte, ello supone, en la misma distancia, un porcentaje de aproximadamente un $7 \%$, es decir casi del doble de pendiente, pues se arranca desde un nivel de altura unos 10 metros inferior y además no hay pendiente constante, siendo primero un terreno casi plano y al final muy brusco ${ }^{13}$.

Esto nos hace suponer que los caminos más antiguos de subida o bajada a la colina seguirían la rampa citada del sudoeste. Es por tanto normal que tal rampa constituya un eje viario respetado por las construcciones, de manera que uno de sus lados quedó como línea fronteriza de la puebla nueva del este, tras la ampliación de entorno a 1256, y a esa rampa se abrieron las bocacalles de las rúas de Cuchillería, Pintorería y Judería.

\section{Sinopsis histórica}

Resumiendo los datos que se van desprendiendo de las aportaciones de la arqueología y del estudio histórico, podemos esbozar, en rasgos muy generales, pues las fechas indicadas no pretenden ser más que una referencia, un estado de la cuestión en cuanto a las fases de evolución urbana de la colina:

13. Los desniveles los calculo en el arranque de la pendiente, al SE desde la zona del Hospital de Santiago, a unos 528 m s.n.m., hasta el pie de San Vicente, que ronda los 544 m; y los del $\mathrm{N}$ desde los $517 \mathrm{~m}$, por la zona de la calle portal de Arriaga en el cruce con Simón de Anda, hasta la plazuela de la catedral a unos 543 m s.n.m. 
Fase 0.- Evidencias, halladas en prospecciones o excavaciones arqueológicas, de fragmentos cerámicos romanos descontextualizados. Queda por determinar hasta qué punto se dio algún tipo de ocupación estable en las etapas prehistórica y romana. Ya se han comprobado restos de habitación, datables en el siglo VII, al pie de la colina, en la plaza meridional, lugar abrigado y cómodo, extramuros de lo que será la villa medieval.

Fase 1.- (c.700-c.1025). Aldea de Gastehiz, configurada en los alrededores de la primitiva iglesia de Santa María, de la que quedan restos de construcción, silos y tumbas. Dos enigmáticos relieves esculpidos pueden recordarse: un gran sillar con tres rosetas incisas intestado en un contrafuerte de la iglesia gótica, y una cabeza rudimentaria hallada sin contexto, junto a la cerca del Zapardiel (ahora en el Museo de Arte Sacro). Sabemos que Gastehiz era un enclave próspero, con capacidad, hacia el año 1000, para entregar 3 rejas de hierro a San Millán de la Cogolla. Quizá eso suponga la existencia de por lo menos una treintena de casas, formando uno de los núcleos más poblados de la Llanada.

Fase 2.- (c.1025-1180). Recinto protegido con un firme muro iniciado en el siglo XI y completado en el siglo XII. La iglesia de San Miguel se alza ya extramuros al sur de la villa. Probablemente le acompaña, sobre el espolón meridional, la fortificación de San Vicente y, entre las dos, protegen la puerta principal del recinto, abierta en el extremo sur.

Fase 3.- (1181-1200). Cambia el status y el nombre de la población (Nova Victoria) con la concesión del Fuero de 1181 por Sancho VI el Sabio de Navarra. Atracción demográfica que va poblando la superficie del recinto de la villa de Suso y forma tres calles convergentes en sus extremos. Robustecimiento de todo el sistema defensivo en altura de la muralla, puertas y torres. Un tenente, Pedro Ramírez, ostenta al menos 15 años el mando militar de la plaza, en nombre del rey navarro. Asedio de la villa desde el verano de 1199 a enero de 1200, en que se rinde al rey castellano Alfonso VIII, tras recibir el permiso de Sancho VII el Fuerte para hacerlo.

Fase 4.- (1201- c.1250). Nuevas posibilidades de expansión comercial bajo la tutela de Castilla. Incendio en la Pascua de 1202. Los destrozos y la presión demográfica hacen desbordar el límite de las murallas por el oeste. Surge una puebla nueva, no un simple arrabal, planificada con tres calles paralelas, escalonadas de manera regular. En su longitud van cortadas por cantones y se forman manzanas dobles. Se atribuye la organización al impulso de Alfonso VIII. La línea exterior se cierra con una cerca y se inicia la construcción de la parroquia de San Pedro, robusteciendo el flanco oeste.

Fase 5.- (c.1251-c.1300). Ahora el impulso renovador puede atribuirse al rey Alfonso X el Sabio, con tres estancias documentadas en Vitoria: 1255-56, 1270 y 1276-77. Se completa el juego simétrico del trazado urbano con otra puebla que extiende también tres calles escalonadas por el este. El mismo sistema de cantones, manzanas, puertas exteriores sobre la cerca, y la edificación 
estratégica de una iglesia para compactar el flanco de levante. Honrando al Santo patrón que daba nombre al rey, se dedica a San Ildefonso. Una parte de esta puebla, y el barrio de Santo Domingo, al norte, no habrán compactado su poblamiento, esperando a los dos siglos posteriores para completar el trazado homogéneo y la ocupación plena del casco medieval.

Una fuente preciosa y excepcional, dada la abrumadora carencia en esta zona de documentación altomedieval, lo constituye el conocido documento De ferro de Alava o de la Reja de San Millán, que, remontándonos al que fue su original, copiado posteriormente, y que es fechado hacia 1025 por consenso general ${ }^{14}$.

Se ofrece en él una lista de 307 lugares, distribuidos en 22 alfoces o comarcas, englobadas en lo que se ha Ilamado Alava nuclear ${ }^{15}$. El recuento general de la recaudación enumera 386 rejas de hierro y 4 carneros que son anualmente ofrecidos al monasterio de San Millán. Tal información es de incalculable valor para múltiples aspectos históricos. Ahora sólo nos centramos en que ya está presente Gastehiz en la lista, dentro del alfoz de Malizhaeza, contribuyendo con tres rejas de hierro, lo que supone la aportación máxima constatada. Con él se limitan a nueve núcleos los que son capaces por sí solos de aportar tres rejas: en las riberas del Zadorra: Maturana, Víllodas y Nanclares de la Oca, en laderas de los Montes de Vitoria: Ios de Eguileta, Hijona, Lasarte y Armentia, en alturas dominantes: Argomaniz y Gastehiz. Todos ellos se localizan en la misma comarca natural del occidente de la Llanada alavesa. Gastheiz muestra un lugar central dentro del conjunto, dejando a cuatro de las poblaciones más nutridas al sur y a otras cuatro al este.

Por tanto, más de 150 años antes de otorgarle Sancho el Sabio su carta de fundación, la colina destacaba ya por ser uno de los núcleos más poblados, aún muy modestamente, de su entorno, en equivalencia con Armentia, sede un

14. Consta en una donación realizada al monasterio de San Millán en 1080 por Muño Alvarez de Ilharraza de una viña en Berantevilla de Alava, que actúa como confirmante Dominico Peregrino collector votorum testis, es decir el que recolectaba en esta zona las ofrendas del voto para San Millán de la Cogolla. LEDESMA RUBIO, María Luisa, Cartulario de San Millán de la Cogolla (1076-1200), en "Textos Medievales" 80, I.E.R.-Monº de S. Millán de la CogollaAnubar ed., Zaragoza, 1989, n 31, p. 32.

15. LANDAZURI, José Joaquin de, Obras históricas sobre la provincia de Alava, (17801799), reed. Vitoria, Dip. Foral de Alava, 1976, vol. IV, pp.41-44. LLORENTE, Juan Antonio, Noticias históricas de las tres provincias vascongadas... Madrid, 1806-1808, vol. III, pp.342352. FITA, Fidel, La reja de San Millán, en B.A.H., 3 (1883), pp.353-361. SERRANO, Luciano, Cartulario de San Millán de la Cogolla, Madrid, 1930, pp.103-106. CARO BAROJA, Julio, Alava en la llamada "Reja de San Millán", en "Historia General del País Vasco", Edad Media I, vol III, San Sebastián, Haranburu, 1980, pp. 111-117. 
tiempo del antiguo Obispado alavés, precisamente en el momento de la recaudación de las rejas.

Otro dato singular que ofrece el citado documento de la Reja es el de las demarcaciones en alfoces, cada uno con una quincena o veintena de localidades que aportan rejas. Los alfoces constituyen pequeñas demarcaciones naturales, delimitadas por colinas o ríos. La llamada Alava nuclear y especialmente la Llanada contribuía de manera unitaria al monasterio de San Millán de la CogoIla, sin lagunas territoriales y sin ningún desierto poblacional, del que se hablaba en un tiempo por no haber afinado en la lectura de la copia que hay del documento, que casi esconde el distrito VIII alfoces, al este de Gasteiz, entre el elenco de Langrares ${ }^{16}$.

Ya en un documento del Cartulario de San Millán fechado en 1089, aparece el patronímico Gasteiz, correspondiente a Alvaro Gonzalvez de Gasteiz, de manera que se suma a la larga serie de apellidos, compuestos de patronímico y de un topónimo del entorno, característicos de la zona ${ }^{17}$.

Una curiosidad etimológica ha llevado a varios investigadores a desentrañar el posible significado del topónimo Gasteiz, tal como aparece en el documento citado de la Reja, o Gastehiz, como aparece en el apellido de Alvaro González de Gasteiz (1089) y en el fuero de 1181, indicando el solar de fundación de Vitoria en 1181. Para Caro Baroja podría ser un antropónimo del tipo de " Garceiz " de García, y cabría reconstruir un nombre o apodo "Gastia », para lo cual valdría el apoyo que ofrece la existencia de "Gastiain » en el límite de Navarra con Alava. Coincide la opinión de otro filólogo, Alfonso Irigoyen, que asegura que deriva del antropónimo correspondiente al nombre vasco de persona " Gaste $»^{18}$.

16. Curiosamente se comprueba que seis alfoces están agrupados de forma radial en torno a un recodo del río Zadorra, en el occidente de la Llanada alavesa. Ese punto apenas dista $3 \mathrm{~km}$ de la colina de Gastehiz. Una vez más se demuestra la centralidad del emplazamiento que determinará el éxito de la futura villa. LÓPEZ DE OCÁRIZ ALZOLA, José Javier, Las unidades de población entre 1000 y 1300: sus formas de agrupación y sus iglesias, en: "Congreso de Historia de Euskal Herria", t.II. "Instituciones, Economía y Sociedad (siglos VIII-XV)", II Congreso Mundial Vasco, San Sebastián, ed. Txertoa, 1988, pp.473-488.

17. LEDESMA RUBIO, María Luisa, Cartulario de San Millán, nº 186, p.129.

18. CARO BAROJA, Julio, "Toponimia más enigmática", en Historia General del País Vasco, Edad Media I, vol III, San Sebastián, Aramburu, 1980, p. 280. IRIGOYEN, Alfonso, "Sobre el topónimo Gasteiz y su entrono antroponímico", en "Congreso de Estudios Históricos : Vitoria en la Edad Media », Vitoria-Gasteiz, 1982, pp.621-652. Es un tema que puede aún dar qué pensar a los especialistas. Así decía hace 250 años Floranes: en la cortísima Aldea de Alava, que hasta entonces se llamó " Gastheyz », nombre vascongado, cuya traducion ignoran oy los más noticiosos de esta lengua. FLORANES Y ENCINAS, Rafael: Memorias y Privilegios de la M.N. y M.L. Ciudad de Vitoria, 1775, en "Biblioteca de Historia Vasca. Colección de obras y documentos inéditos relativos a la historia del País Vasco", vol 6, Madrid, 1922, p.27. 
No es el momento de ahondar en el trasfondo social, económico, demográfico y político que sostiene y da vida al fenómeno urbano que brota en Vitoria. Son ya muchos los trabajos de investigación, las recopilaciones documentales y los análisis históricos de variado enfoque. También comienzan a aparecer reseñas que informan sobre una parte importante de este gran esfuerzo de aproximación al tema ${ }^{19}$.

\section{El fuero de población de Vitoria}

Las Ilamadas cartas pueblas, fueros municipales otorgados para atraer población en las nuevas villas de fundación real, son un fenómeno común a toda Europa desde mediados del siglo XI hasta el siglo XIV. En los territorios vascos de Alava, Vizcaya y Guipúzcoa se vivió un intenso proceso de urbanización entre la segunda mitad del siglo XII y la del siglo XIV: casi 70 villas fueron fundadas en menos de 250 años.

El proceso más temprano se da en Alava pues es donde se inicia el proceso (fuero de Salinas de Añana en 1140) y basta con dos siglos (1140 y 1338) para la fundación de las 23 villas que conservan su fuero ${ }^{20}$.

El territorio alavés, en torno a Vitoria, vive su mejor momento fundacional entre 1180 y 1280, aunque algunos casos se anticipan, como los de Salinas de Añana en 1140, y Laguardia en 1164. La fundación de Vitoria, en 1181, desencadena una serie de fundaciones: Antoñana (1182), Bernedo (1182), La Puebla de Arganzón (refección de 1191), Labraza (1196), Labastida (1242), Treviño (1254), Salvatierra (1256), Corres (1256), Santa Cruz de Campezo (1256), Contrasta (1256), Peñacerrada (antes de 1322, quizá hacia 1256), Salinillas de Buradón (1264), Artziniega (1272), Berantevilla (1312), San Vicente de Arana (1326), Villarreal de Alava (1333), Alegría de Alava (1337), Elburgo (1337), Monreal de Zuya (1338), y Lagrán en fecha desconocida. También se conserva la concesión de carta de privilegios al valle de Valderejo en 1273.

En una coyuntura compleja, el año 1181, el rey navarro Sancho el Sabio, vir magnae sapientiae, desde Estella, otorgó, basándose explícitamente en el Fuero de población de Logroño, concedido en 1095 por Alfonso VI, el

19. DÍAZ DE DURANA, José Ramón, «El fenómeno urbano medieval...», pp.59-109. También merece consultarse: GONZÁLEZ MINGUEZ, César, Las raíces medievales de la ciudad actual: un ejemplo de la Corona de Castilla, Vitoria, Caja Vital, 1997.

20. Incluimos en el elenco los casos de Lapuebla de Arganzón y de Treviño, que en ese momento viven circunstancias históricas comunes al resto de Alava, y suponemos que la fecha ignorada del fuero de Lagrán, sea coincidente con el marco señalado, entre 1140 y 1338 . Sobre el tipo de cartas pueblas, ver: ORELLA UNZUE, José Luis, "El modelo riojano-alavés de Vitoria, de fueros francos, y su difusión en Guipúzcoa", en Vitoria en la Edad Media, Vitoria, 1982, pp. $711-723$. 
documento fundacional, o carta puebla de 1181: Yo Sancho, por la gracia de Dios rey de Navarra otorgo esta carta de confirmación y corroboración para todos vosotros, mis pobladores, tanto presentes como futuros, de la Nueva Victoria. Me ha complacido de forma benévola y razonada poblaros en dicha villa, a la que he impuesto nuevo nombre, es decir: Victoria, que anteriormente se llamaba Gasteiz. Y os concedo que en todos vuestros juicios, procesos y negocios tengáis y conservéis siempre el mismo fuero que tienen y gozan los burgueses de Logroño ${ }^{21}$.

Vista desde nuestra perspectiva, la decisión de implantar una villa en la colina de Gasteiz, se mostraba como el fruto de un plan coherente y bien meditado. Un factor muy importante es que reúne un nudo de comunicaciones. Desde época romana está atestiguado el paso constante por sus inmediaciones de la calzada que unía Astorga con Burdeos, documentada en el Itinerarium de Antonino, como el Iter XXXIV ab Asturica Burdigalam. Se puede seguir su trazado a un kilómetro al sur de la colina, entre Armentia y Arcaya (antigua Suessatio), cruzando de oeste a este en su travesía por el centro de la Llanada alavesa. Recientemente los hallazgos arqueológicos han sacado a la luz en Mariturri una mutatio o estación de parada del correo imperial, además de un cruce de caminos en dirección norte-sur, por tanto transversal a la calzada romana y un centro de explotación agropecuaria. Hacia el norte cabe pensar que seguiría los pasos de montaña para llegar a la costa, y hacia el sur buscaría las tierras soleadas del valle del Ebro. Y no podemos olvidar que Vitoria será recorrida por múltiples peregrinos del camino jacobeo, en el viaje de ida o, quizá con más intensidad, en la ruta de regreso a sus países de origen ${ }^{22}$.

\section{Morfología urbana: la "acrópolis" de Villa Suso}

Aunque carecemos de suficientes apoyos documentales $y$, a la espera de que se inicie un programa arqueológico global para el conjunto de Villa Suso, avanzaremos una reflexión sobre los factores que pudieron pesar en la elección y establecimiento en la colina de Gasteiz. Como tales factores podemos enumerar: la configuración peculiar del emplazamiento, la tipología constructiva, una

21. Ego Sancius Dei gratia rex Nauarre facio hanc cartam confirmationis et roborationis uobis omnibus populatoribus meis de noua Victoria tam presentibus quam futuris. Placuit mihi libenti animo et sana mente populare uos in prefata uilla cui nouum nomen imposui scilicet Victoria, que antea uocabatur Gasteiz, et dono uobis et concedo ut in omnibus iudiciis et causis et negociis uestris illud idem forum habeatis et omni tempore teneatis quod burgenses de Lucronio habent et possident. Aunque ha sido diversamente publicado, por brevedad citamos la edición de MARTíNEZ DíEZ, Gonzalo, Alava Medieval, t I, Vitoria, Diputación Foral de Alava, 1974, pp.223-226.

22. PORTILLA, Micaela J., Una ruta europea. Por Álava, a Compostela. Del paso de San Adrián, al Ebro, "Alava. Monumentos en sus historia" n 10, Vitoria, Dip. Foral de Alava, 1991. 


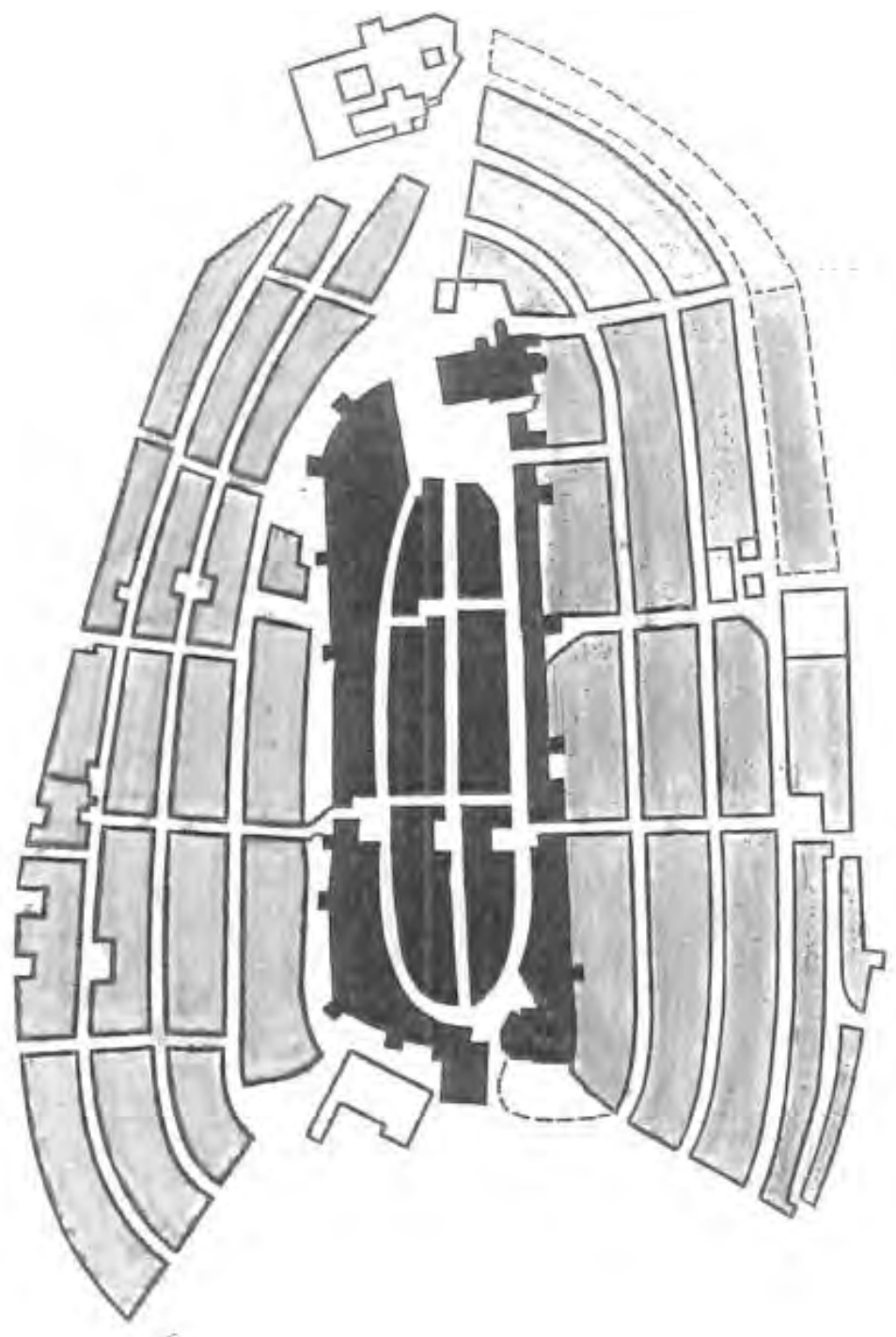

Figura 2: Croquis mostrando las tres fases de desarrollo urbano de Vitoria, la central, del siglo XII, y las laterales, del siglo XIII.

adaptada a la habitación, otra a la defensa, los materiales pétreos, que en forma de mampuestos calizos son accesibles en el entorno inmediato, los edificios de 
uso público que allí podrán concentrarse, el grado de ordenación o planificación progresivamente establecido desde las instancias superiores.

En la evolución de la villa resultaron decisivos tanto el condicionante orográfico de la colina, como la intencionalidad primera de aprovecharlo como plaza fortificada. De ahí se deriva que el diseño del baluarte quedaba determinado por la forma de la colina, y que una vez que se establecía una línea de cerramiento, aún en la fase probable de una empalizada previa, ya se configuraba un tipo de trazado urbano, forzosamente adaptado a su marco exterior. Por ello el éxito y la estabilidad futura de la operación estribaba en la positiva interacción de la orografía, del entramado defensivo y de la adaptación urbana a los anteriores condicionantes.

Un perfil de línea defensiva recorriendo el borde superior de una colina es ya eficaz, pero hay que cuidar sus puntos débiles y fortificar la estructura con nudos de mayor potencia. Una típica solución, conocida en poliorcética, consiste en marcar una sucesión de torres que aseguren el control de vigilancia y una solvente defensa de las líneas, sobre todo cuando los escarpes naturales y la muralla dificultan el ataque ${ }^{23}$. En cambio, como puntos débiles se pueden considerar los de más fácil acceso, donde por lógica también se han practicado las puertas de entrada. Ahí es necesario intensificar la robustez defensiva, y para ello es necesario prever una fortificación sobre, o contigua, a la puerta.

Es normal el situar en esos puntos edificios públicos de gran porte, con muros sólidos, torres para atalaya y mantenimiento constante. El binomio es perfecto si se combina la función defensiva con la religiosa, y de ahí se deriva el modelo de templo-castillo protegiendo la puerta. Esa es la solución más económica en un lugar no demasiado privilegiado por grandes dispendios señoriales o reales. Atendiendo a lo que conocemos sobre las mentalidades de la época, el componente de protección más alto venía dado por la fe religiosa. Encomendar la iglesia a Dios y los Santos era garantizar su amparo y valimiento. El culto y los rituales religiosos robustecían tal confianza y, al depositar los cuerpos de los fallecidos en los cementerios anexos a las iglesias, incluso el poder insondable de los antepasados se sumaba a los factores de salvaguardia.

23. Según el manuscrito de Francesc Eiximenis (1330-1409), escrito entre 1385 y 1386 y sacado a la luz por don Luis Monreal y Tejada, de estas formas se puede atacar un castillo: con ballestas y arcos, con dardos y con piedras en hondas, escalando el muro por varios puntos a la vez con escalas, cavando y socavando el muro hasta conseguir que éste se derrumbe y por el boquete entrar al asalto, lanzando piedras contra el muro o dentro de la villa con máquinas; con gatas y carretas acercándose al muro para demolerlo y abrir brecha en él, mediante la construcción de bastidas o castillos de madera a fin de aproximarse en posición ventajosa y saltar sobre la fortaleza, por pacto o entrega, mediante sed o hambre... Otros muchos consejos sobre la ciudad ofrece Eiximineis. MARTIN, José-Luis, La ciudad y el príncipe, "Publicacions i Edicions de la Universitat de Barcelona", Barcelona 2004. 
En el caso de la villa que estudiamos, la planificación se aseguró mediante templos-bastiones en ambos polos: al Norte el de Santa María, al Sur los de San Miguel y San Vicente, e incluso éste último tan utilizado como castillo que como lugar de culto. Curiosamente sabemos que también en la ciudad medieval Nájera el castillo de San Vicente contaba en su interior con una pequeña iglesia dedicada a San Vicente, de la que ahora no queda nada ${ }^{24}$. ¿No podría haber sido semejante la situación en San Vicente de Vitoria en su época más antigua? No nos resulta fácil imaginar hoy la coexistencia, en el interior de un castillo, de una parroquia con sus cultos. Por fin, en clima pacificado, el castillo es derruido y se reconstruye la iglesia con nueva fábrica al finalizar la Edad Media.

Las tipologías utilizadas en la villa de Vitoria no son nuevas, sino ya verificadas en otros casos, pero resultan muy ajustadamente acomodadas al perfil geográfico, e histórico, de manera que aunque cambiaron las circunstancias y evolucionó expansivamente la población, no hubo dificultad en acomodar las nuevas estructuras yuxtaponiéndolas a las anteriores. La planificación de nuevas pueblas o ensanches suponía desarrollar de nuevo el entramado de fortificaciones, cuya línea exterior definía el ámbito urbano disponible, a la vez que restringía la expansión al espacio dentro de ella, forzando a la máxima compactación en el caso de un amplio crecimiento. Esa línea externa del recinto amurallado marcaba a la vez el distintivo entre urbano y rural, entre el espacio aforado y el suelo foráneo.

En la planificación se advierte una concepción clara y sencilla, una adaptación flexible a los condicionantes dados, a través de unos ejes de simetría que posibilitan soluciones prácticas. De nuevo, al configurar las dos pueblas laterales, que flanqueaban por los costados a la acrópolis fundacional, la lógica anterior condujo a retomar el modelo de templo-castillo protegiendo la puerta, para situar las iglesias fortificadas en los extremos del nuevo eje Este-Oeste. En este caso se trataba de San Pedro, al borde de la cerca occidental, protegiendo el flanco y su puerta, y en el extremo opuesto San Ildefonso, en primera línea de fortificación, centrado en el lienzo de muralla del levante.

Suponiendo que el espacio disponible en la acrópolis quedase plenamente colmatado, hubiera podido albergar quizá hasta un millar de habitantes. Pueden caber holgadamente, en lotes como los que aún son habituales en las calles contiguas, alrededor de 200 casas.

24. GARCÍA TURZA, Francisco Javier, "Morfología de la ciudad de Nájera en la Edad Media", en Actas de la III Semana de Estudios Medievales, Nájera, 1992, I.E.R., Lgroño, 1993, pp. 63-88, nota 13. Addimus etiam vobis et confirmamus ipsam ecclesiam sancti Vicentii, que est in ipso castello. (CANTERA MONTENEGRO, Margarita, Santa María la Real de Nájera (siglos XI-XIV). Madrid, 1987, núm. 42). 
La instalación de Gasteiz en la zona alta, Ilamada luego de Villa Suso, sigue el clásico modelo de colina fortificada, como haciéndose eco del dicho evangélico: no puede ocultarse una ciudad construida sobre un monte ${ }^{25}$. Así estaban construidas Troya, Micenas, la acrópolis de Atenas, Argos, Jerusalén: el Monte de Sión, Roma sobre sus siete colinas, y tantas otras. Por eso los textos medievales del siglo XII recomendaban elevar la ciudad sobre un mons modicus (un altozano ${ }^{26}$. Con su muralla en torno, Vitoria configura un tipo de acrópolis muy característica, descollando en la llanura.

Como ya hemos anticipado, la colina no ofrece un relieve exageradamente grande, pero el carácter plano del entorno le hace destacar y parecer más descollante que su tamaño real. Se sitúa a unos $550 \mathrm{~m}$ sobre el nivel del mar, cuando el zócalo de tierras en su base queda 30 metros por debajo, de forma que su perfil le delata como la única prominencia en las riberas meridionales del río Zadorra, hacia el centro del Ilano alavés.

En cuanto a sus mediciones máximas, debemos contar con las alteraciones que hoy presentan la topografía original los muros y construcciones establecidas. A la superficie superior amesetada se le ha calculado sólo 3 Has, pero quizá se le pueda adjudicar como terreno disponible al menos 4 Has, frente a las casi 21 Has del casco medieval completo de Vitoria. Hablando genéricamente se puede atribuirle casi 400 m de largo, por 100 ó 120 m de anchura media. Si se compara este cálculo aproximado de la villa de Suso, con las superficies estimadas en otras villas alavesas fundadas entre el siglo XII y el siglo XIV, sólo le superarían las de Laguardia y Salvatierra, pero hay que tener en cuenta que el ensanche hacia la villa de Yuso con la adición sucesiva de las dos pueblas, permitirá a Vitoria multiplicar por cinco su extensión inicial de la cima de la colina. En cambio las demás villas apenas llegarán a desbordar muy tardíamente el corsé de sus murallas o de su recinto medieval. Y al contemplar las pendientes que acompañan por los lados a la acrópolis de Laguardia, podemos imaginar la osadía que supondría el planificar sendos trazados de calles escalonadas en sus repechos. Por ello, allí, las edificaciones exteriores, tardías, se han bajado directamente al Ilano.

La comparación subraya los parecidos y las diferencias. Salvatierra nace sin muralla y esa empresa costosa resultará una corvea posterior. Pero en todos los casos, las iglesias son moles y fortalezas que se integran en el sistema defensivo: así lo es la torre abacial de Laguardia, y la torre de San Juan como puerta de la villa. En Hagurhain-Salvatierra ambas iglesias: San Juan y Santa María, cuando

25. Non potest civitas abscondi super montem posita. (Mt 5, 14).

26. JEHEL, ... RACINET, ..., La Ciudad Medieval..., p.101. LÓPEZ DE OCÁRIZ ALZOLA, José Javier; BUENO AGERO, Juan Adrián: MORÚA ACHIAGA, Ángel, Vitoria-Gasteiz Espacios \& Tiempos de la Ciudad Histórica. Hiri Historikoaren Eremuak \& Denborak, Ayunt ${ }^{\circ}$ de VitoriaGasteiz, Vitoria, 2008. 
se construyen avanzado el medievo, se dotan de un paso de ronda bien construido. En las tres villas mayores del medievo alavés se disponía una judería, muy importante en el caso de Laguardia, que se alberga en un lugar señalado y algo apartado.

El resultado que vemos ahora en la antigua acrópolis de Vitoria, convertida más tarde en ville morte, puede quizá confundirnos en el trazado de tres calles y sin apenas espacios abiertos. Al comprobar con planos o descripciones relativamente antiguas, advertimos que pudo no ser tan uniforme, pues encontramos alusiones al campillo de los chopos y la expresión subir al Campillo en Vitoria es sinónimo de ir a Villa Suso, de manera que algunas áreas abiertas, como el tal Campillo, pudieron situarse particularmente en ambos extremos del huso. Las excavaciones practicadas hace unos años en el Campillo, permitían apreciar innumerables agujeros circulares de formas variadas, practicados en la roca de base, lo que indica a lo largo de los siglos, múltiples actividades: silos, postes, fondos de vivienda, pequeños aljibes, en una zona de constante ocupación.

Los planos archivados en el Ayuntamiento de Vitoria, trazados en 1825, en 1836 o en 1865, dan pie a que pueda entonces calificarse a Villa Suso de zona verde, pues, sólo en su mitad sur, muestra más zona ajardinada que en todo el resto del casco histórico. Es evidente que ello refleja en época moderna una situación de ville morte, a la que la evolución urbana había conducido a Villa Suso, que ya sólo albergaba contados palacios e iglesias, mientras la vida ciudadana bullía en las zonas bajas.

En cambio, hasta el incendio de 1202, podemos suponer que se dio una compactación urbana en el área alta entonces disponible. Pero, dos siglos después, las cosas habían cambiado mucho. En esa fase bajomedieval ya se había iniciado el proceso de abrir zonas de expansión verde, pues al menos hay un interesante testimonio de la existencia de huertos y vergeles. Según consta en el archivo municipal, en julio de 1428 solicitó Doña Constanza de Ayala, viuda de Don Pedro de Guevara, al Concejo vitoriano permiso para un pasadizo elevado sobre la calle, desde su palacio a unas casas con huertas ${ }^{27}$.

Otra constatación de gran interés la podemos obtener a partir de la reacción y de la respuesta del concejo. Advierten que no había precedente sobre tal tipo de petición: por quanto era cosa nueba en la dicha villa nunca tal cosa fue

27. Que les ploguiere de le dar lugar en que ella fisiese faser un pontesco para pasar por el atrabesando la calle desde las sus casas e palaçios donde ella bibe fasta las casas que agora nuebamente ha hecho que son de partes delante es contra San Vicente porque ella pudiese ir a folgar e a tomar plaser en un bergel e huerta que tiene de red de las dichas casas e que al dicho conçejo le ploguiese de le dar licencia para faser el dicho pontesco. Libro de la Cámara del Concejo de la Villa de Vitoria, (A.M.V., secc. 112, leg. 21, fol. 35 v.), en DÍAZ DE DURANA, José Ramón, "Vitoria a fines de la Edad Media (1428-1476), en "Azterlanak", 2, Vitoria, 1984, Apéndice documental, A.M.V., n 145 , pp.238-239. 
pedida nin fecha. Pero, sin duda, la alta condición social de Doña Constanza obligaba al consistorio a plegarse a su petición, por ello se lo concedieron de manera provisional, pero con condiçión que todo tiempo quel dicho conçejo e a los alcaldes e regidores de el ploguiese o fuera su boluntad que lo pueden derribar e desatar e que la dicha $D^{a}$ Constanza se someta a todo ello. Así lo aceptó Doña Constanza. Suponemos que, como mucho, el pontiso duró hasta la caída en desgracia de los Ayala en la revuelta fallida de 1521 protagonizada por D. Pero de Ayala el Comunero. Al menos, del planteamiento de 1428, surgió una normativa municipal: que de aqui adelante persona alguna de la dicha billa nin de fuera della que non sea en dar lugar nin liçençia nin mandamiento alguno para faser semejante pontiso... Todo ello prueba algo ya supuesto: la existencia de un habitual control de los trazados urbanísticos desde la Edad Media.

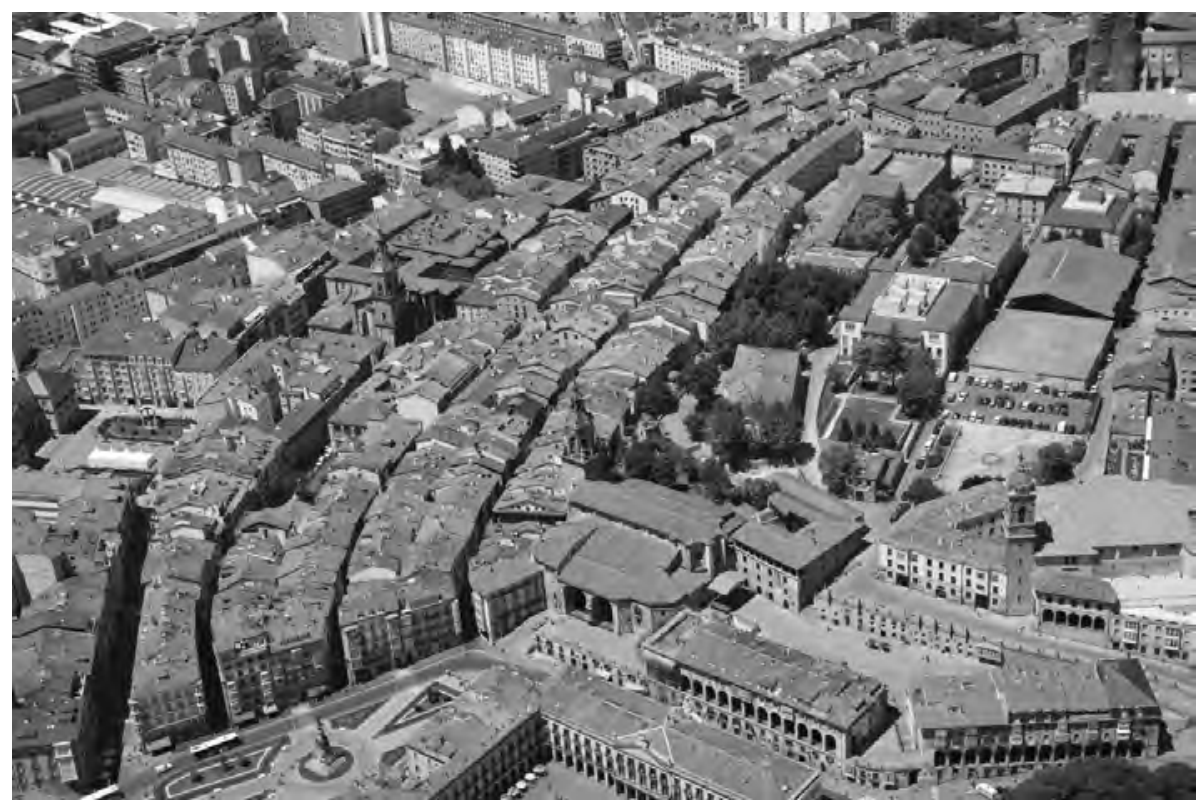

Figura 3: En la vista aérea se aprecia el resguardo meridional de "Villa Suso" con dos iglesias: San Miguel y San Vicente, y el refuerzo del flanco de poniente con la iglesia de San Pedro. FOAT. 


\section{La ampliación en el siglo XIII. Dos nuevas pueblas ${ }^{28}$}

En primer lugar se formó la Puebla nueva del Oeste. Hacían falta poderosas razones para dar el paso hacia la ruptura y desbordamiento del límite amurallado, en una villa casi recién fundada. Un dato relevante, por suerte documentado, es el incendio de 1202, que ofrece una explicación concluyente.

Los diversos relatos historiados se han hecho eco del triste suceso del 1202, recordando la breve noticia del Cronicón antiguo de la Calenda de Burgos, un calendario necrológico manuscrito del siglo XIII que recopila datos con límite en la batalla de las Navas de 1212: Era MCCXL fuit Victoria combusta, et multi homines et mulieres in die Parasceve, nocte tamen praecedente. Es decir, que en la era 1240, año de 1202, hubo un gran incendio en Vitoria, que duró el día de Pascua y la noche antecedente en el cual perecieron muchos hombres y mujeres.

Era habitual e inminente el peligro de incendios en poblaciones construidas con estructura de madera y techumbre vegetal. La ciudad de Rouen ardió seis veces entre 1200 y 1225 . Vitoria tres entre 1202 y 1240². Incluso la misma Carta Puebla de Vitoria en 1181 alude a estas endebles construcciones: Dondequiera que encontréis madera para construir casas y leña para quemar, cogedla ${ }^{30} \ldots$

Al ser un dato tan escueto, no podemos calcular el alcance real del incendio. Se suele argumentar que destruyó hasta tal punto la población de la villa alta que,

28. Entre otras fuentes de gran interés recordamos ahora a: VICTORIA, Fray Juan de, Nobiliario alavés, (obra del siglo XVI), transcrita y publicada por VIDAURRAZAGA, José Luis, ed. La Gran Enciclopedia Vasca, Bilbao, 1975, lib. 1º, cap. 11, p.53. LANDAZURI, Juan José, "Historia civil, eclesiástica, política y legislativa de la M.N. y M.L. Ciudad de Vitoria", en: Obras históricas sobre la provincia de Alava, (del siglo XVIII, reed. por Diputación Foral de Alava, 4 vol.), Vitoria, 1976, t I. BECERRO DE BENGOA, Ricardo, El libro de Alava, Hijos de Manteli, Vitoria, 1877 (reed Dip. For Alava, 1983). SERDÁN Y AGUIRREGAVIRIA, Eulogio, El libro de la ciudad. Historia de Vitoria, 2 vols., ed. Social Católica, Vitoria, 1926-1927. ALFARO FOURNIER, Tomás: Vida de la ciudad de Vitoria, Magisterio Español, Madrid, 1951. A.A.V.V., Pasado y Presente. 10 años de gestión. Rehabilitación Integrada del Centro Medieval de Vitoria Gasteiz. Departamento de Centro Histórico, ed. Ayuntamiento de Vitoria Gasteiz, Vitoria, 1995. PORRES MARIJUAN, Rosario (dirigido por), Vitoria, una ciudad de 'ciudades', (Una visión del mundo urbano en el País Vasco durante el Antiguo Régimen), Universidad del País Vasco, Euskal Herriko Unibertsitatea, Vitoria, 1999. GAUTIER DALCHÉ, JEAN, Formation et développement du réseau urbain médiéval en Alava, en «Congreso de Estudios Históricos: Vitoria en la Edad Media», Vitoria-Gasteiz, 1982, pp.219-237.

29. Hase quemado Vitoria muchas veces casi toda y hoy está por esto gran parte de ella yerma, y el quemarse era fácil por ser casi toda de tabla. Quemóse el año 1202 y 1208 y 1240 y 1390 y 1423 . VICTORIA, Fray Juan de, Nobiliario alavés, lib. $1^{\circ}$, cap. 8, f. 56, p.39.

30. Et ubicumque inueneritis maderam pro facere domos et ligna pro cremare accipite ea sine ulla contraria, exceptis cognitis defensis in quibus non licet accipere. CARO BAROJA, Julio, Los Vascos, Madrid, Istmo, 1971, p.113, nota 2. MARTínEZ DíEZ, Alava Medieval, t.l, pp.223-224. 
en vez de construir sobre los escombros, prefirieron descender hacia la ladera. Por la previsible gradación lógica, el ensanche progresaría de arriba abajo. A comienzos del XIII, aún estaba demasiado próximo el asedio y la inseguridad, dadas las tensiones entre Castilla y Navarra. Imaginamos, por tanto, que la puebla empezaría formando un arrabal arrimado a San Miguel. De hecho, aún actualmente, la lotificación de la $1^{\text {a }}$ vecindad es muy apretada y la calle muy estrecha, lo que parecen indicios de antigüedad. Pero quizá no podemos fiarnos de que el parcelario actual sea fiel reflejo del original del siglo XIII. Al menos podemos asegurar que el orden de vecindades, tras la de Villa Suso, siempre ha empezado por este primer tramo de la calle Correría. Eso está bien documentado.

El trazado de esta primera calle sigue una línea paralela a la muralla alta, liberando en las traseras por ese lado un espacio libre para pequeñas huertas, o porque había servidumbre en cuanto a la muralla para su mantenimiento. En cambio, la manzana del lado bajo de la calle habilita detrás un caño de desagüe, que respetarán los siguientes habitantes cuando una nueva calle por abajo se articule en paralelo, aprovechando en común ese espacio de vierteaguas. Eso ha favorecido durante siglos el saneamiento y la habitabilidad sostenible de estos barrios góticos.

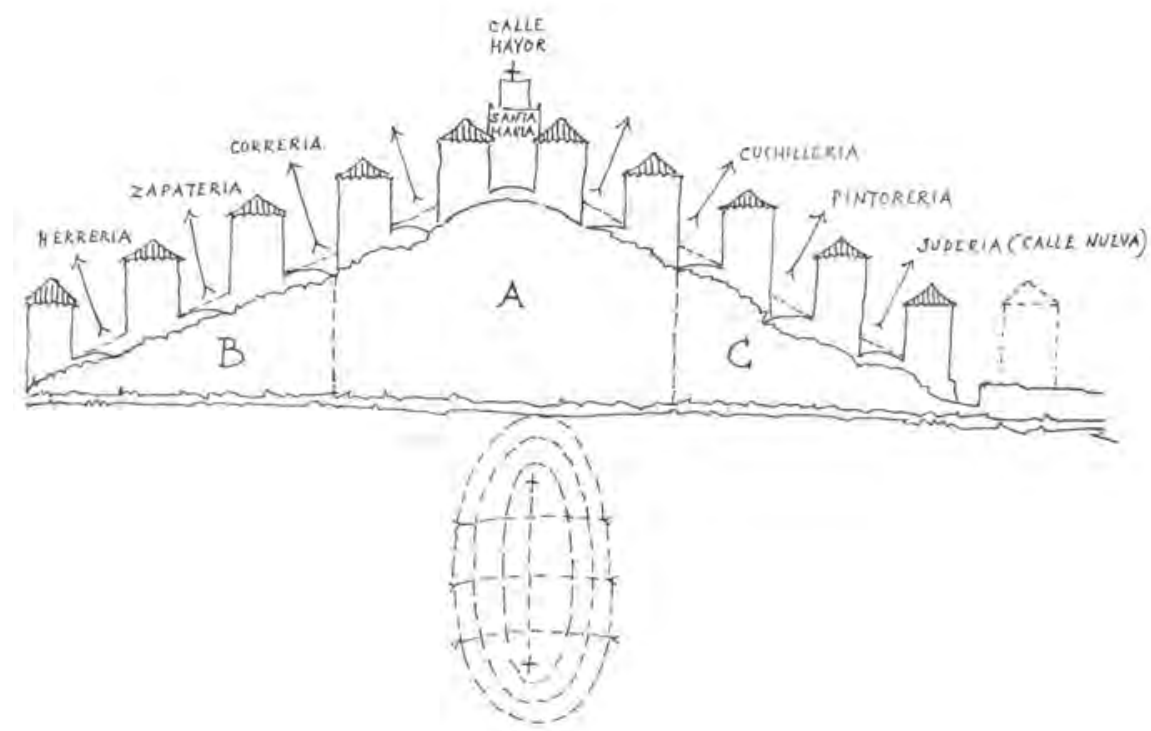

Figura 4: Croquis muy expresivo del perfil de la colina de Vitoria, dibujado por D.Julio Caro Baroja. Cada área: A, B o C muestra sus tres calles escalonadas. (CARO BAROJA, Julio, Alava del siglo VIII al siglo XII, "Ha Gral P.Vasco. Edad Media I", vol III, 1980, p.26). 
El mismo procedimiento de situar cada una de las tres calles en la gradación espaciada de las curvas de nivel, permitió dotar a las tres de su parcelación equilibrada, con manzanas dobles entre ellas. Considerando como un referente antiguo el título establecido para las tres calles: Correería (abreviado luego en Correría), Zapatería y Herrería, encontraríamos un afincamiento de la artesanía del cuero en dos de las calles, las superiores, lo que encaja bien con los datos que nos hablan de la Adobería, donde los curtidores adoban los cordobanes y las suelas ${ }^{31}$, dejando que las tenerías, a base de agua limpien, curtan y preparen las pieles.

El río Zapardiel, un arroyo que corre en la base de la colina por el poniente, podía surtir de unos mínimos del agua que se necesitaba. Curiosamente, otro río con el mismo nombre bordea la ciudad de las Ferias, Medina del Campo, y ambas coinciden en el dato de que a ese río también se vertían los deshechos de las carnicerías, por lo que hay quejas desde antiguo sobre su insalubridad y malos olores ${ }^{32}$. La relación de Madoz, recuerda que el río Avendaño, en que desemboca el Zapardiel, después de alimentar un batán y varias fábricas de curtidos... desemboca en Arriaga en el río Zadorra.

Las tenerías necesitan mucha agua, tanino, ciertos minerales, en particular la sal, por ello los métodos de curtido, raspando los cueros, convertían las tenerías en zonas sucias y malolientes, y las normas municipales exigían que se alejasen de las zonas habitadas.

Una segunda fase consistía en teñir y dar forma al cuero o piel ya curtida, para fabricar correas, zapatos, guarnicionería. Esta artesanía era admitida en zona habitada. Las cofradías de zapateros fueron pronto numerosas, con sus protectores Santa Águeda San Crispín y San Crispiniano, y sus cultos en la iglesia de Santa María, según refiere en el siglo XVI fray Juan de Victoria. También el mismo cronista recuerda que, entre las vestimentas más populares en la ciudad, figuraban los zamarros para los hombres y las zamarras para las mujeres ${ }^{33}$.

El nombre de Zapatería para una calle no parece muy extendido. Curiosamente, el historiador Jacques Heers señala como dato artesanal una calle

31. LANDAZURI, "Historia civil", en Obras históricas sobre la provincia de Alava, t. I, p.8.

32. Indagando en la etimología de Zapardiel, encontramos verosímil que provenga de la abundancia de la zaparda o squalius pyrenaicus, un pez de la familia de los ciprínidos, de unos $25 \mathrm{~cm}$, ahora en peligro de extinción pero que se vendía hasta hace medio siglo en el mercado vitoriano. Quizá el nombre proporcione una pista sobre una mayor regularidad en el caudal del Zapardiel que, en cambio, según el Madoz, a mediados del siglo XIX, Ilevaba tan escasa cantidad de agua que se secaba en verano. MADOZ, Pascual, "Alava", en Diccionario geográfico-estadístico-histórico de España y sus posesiones de ultramar, Madrid, 1845-1850 (ed. facsímil, Vitoria, Juntas Generales de Alava, 1989) (sobre Vitoria: pp.199-215; sobre el Zapardiel, p.208).

33. VICTORIA, Nobiliario alavés, libro $2^{\circ}$, cap. 12 , f. 198 , y libro $1^{\circ}$, cap. 53, p.202, f.162 v. 
Zapatería en la ciudad medieval de León, pero no parece que se mantiene allí tal nombre ${ }^{34}$.

La forja y trabajo del hierro es la otra actividad que la puebla mantiene, según el nombre que recibió la calle Herrería. También el agua es una de las materias necesarias para este trabajo. Los datos que podemos seguir desde la baja Edad Media y siglos posteriores, hacen suponer que la privilegiada posición de esta calle, más llana y mejor comunicada con el exterior, la convirtieron pronto en calle de cierto impacto comercial, preferida por los viajeros para su alojamiento. En realidad no hay seguridad de que estuviera ahí la primitiva Aduana de Vitoria, de la que ya hay datos en 1289. Pero sí lo estuvo en época moderna, y sabemos que funcionaba como calle de posta. Según su denominación, una calle de la otra puebla del este, la calle Cuchillería, acompañó a la Herrería en la artesanía especializada del metal.

Parece razonable pensar que no se alcanzó a completar durante largo tiempo la plena longitud de las tres calles de la puebla oeste. Todo apunta a que el desarrollo de ellas fuera siempre iniciándose desde el sur, tal como el orden de las vecindades también rubrica. Creemos que pudo detenerse la expansión urbana a nivel de los actuales cantones de la $3^{\mathrm{a}}$ o $4^{\mathrm{a}}$ vecindad, sobre todo de esta última, hacia la altura del cantón ahora llamado de las Carnicerías o de Aldave. Innumerables estudios históricos han comprobado que el avance demográfico europeo se paraliza algo después de 1300, como ya anunció Pirenne hace años ${ }^{35}$.

El cantón modernamente llamado de la Soledad, también era Ilamado cantón de San Pedro, puesto que se cierra por el oeste con la mole de la iglesia de San Pedro. Es el que marcaba el eje de cruce entre la puebla oeste y la del este, pues cruzaba con puerta bajo la muralla alta, proseguía seccionando las tres calles longitudinales de Villa Suso, pasaba al otro lado de la muralla del este y continuaba por el cantón modernamente conocido como de San Francisco Javier o del Colegio, en el área diametralmente opuesta. Ese eje potencia en la villa un bloque meridional con unas características peculiares, muy abierto hacia la plaza del mercado y, tanto por razones climáticas como por las económicas, se mostraba como la zona privilegiada, ambicionada por los más dotados de poder económico y social.

A continuación, viene una franja urbana central, avanzando al oeste hasta el cantón de Anorbín, y en el este hasta el cantón de Santa Ana, ambas protegidas por las iglesias de los costados, y así conformando doce manzanas. Por último

34. HEERS, La ville au Moyen Àge en Occident. Paysages, pouvoirs et conflits, Paris, Fayard, 1990, p.75.

35. PIRENNE, Henri, Historia económica y social de la Edad Media, Madrid, F.C.E., 1980 (Paris, P.U.F., 1933), pp.126-127. 
la franja septentrional, donde se supone que el bloque construido más antiguo tenía como línea de demarcación los paredones del norte de Santa María, dejando el extremo exterior, de urbanización relativamente tardía, para cuando se llegue a colmatar el borde septentrional de la tres calles.

La Iglesia de San Pedro cumplía un papel importante como cierre del cantón de la Soledad, o de San Pedro, que sirve de eje al primer impulso urbano de la nueva puebla, y como reforzamiento defensivo de las cercas sobre el Zapardiel. Sus orígenes arrancan del siglo XIII, aunque su gran etapa constructiva se desarrolla en el siglo XIV, y de su configuración arquitectónica se hablará más tarde. Es interesante constatar que la advocación de San Pedro se repite en un área geográfica no lejana, también por otros templos erigidos en momento y circunstancias similares. Al mismo tiempo sorprende que la entrada a la parroquia vitoriana irrumpe en el cuarto absidiolo de la cabecera, para tener un rápido acceso desde la calle Herrería, ya que el muro del poniente, donde se instalan las grandes portadas, es un muro de cierre, que sirve como cortina de muralla ${ }^{36}$.

El edificio de la iglesia de San Pedro, de mayor altura que el resto de lo edificado en la calle, se adosó a la línea de muralla baja, de manera que sus muros del poniente son de gran espesor. Incluso una referencia de Landázuri, con visos de recoger tradiciones antiguas, usa una curiosa expresión: la muralla fue rompida, para encajar el nuevo bastión-iglesia ${ }^{37}$. En esa zona el muro quedó reforzado con un torreón algo saliente en planta, que coincide con el tramo central de la nave a los pies, justo sobre el medio del coro alto. Por todo ello resultaba inviable practicar una entrada hacia los pies, tal como solía ser habitual, y la entrada principal, según se ha indicado, se abrió por lo que habría sido una de las capillas de la cabecera, al este, que es la parte del templo más próxima a la calle Herrería, su acceso inmediato.

Volviendo sobre el citado torreón, embutido en la fábrica de la iglesia y no bien encajado en ella, habría que estudiar su construcción mediante los métodos de la arqueología de la arquitectura, para determinar si es anterior a la iglesia y queda como testigo de la estructura defensiva inicial de la muralla baja, o bien se necesitaba reforzar ese flanco, aún a costa de alterar el trazado del hastial de la iglesia.

Muy próximo a la cabecera de la iglesia de San Pedro se ubicó el hospital del mismo nombre, fundado por Garci Martínez de Estella, tal como consta en

36. PORTILLA VITORIA, Micaela J. (et alii), "Parroquia de San Pedro apóstol", en Catálogo Monumental. Diócesis de Vitoria. Ciudad de Vitoria, vol. III, ed. Caja de Ahorros Municipal de la Ciudad de Vitoria, Vitoria, 1971, pp. 139-181. PORTILLA, Micaela J., El arte en los templos vitorianos, en Vitoria, 800 años, $\mathrm{n}^{\circ}$ 8, ed. Caja Provincial de Ahorros de Alava, Vitoria, 1981, pp.9-11.

37. LANDAZURI, José Joaquin de, "Historia civil...", en Obras históricas sobre la provincia de Alava, t. I, p.136. 
su testamento de 1396. Siguiendo el curso del Zapardiel, hacia la base noroeste de la colina vitoriana, se instaló en el siglo XIII el convento de Santo Domingo y, según el historiador Landázuri que revisó su documentación, lo fue sobre un palacio y ermita de santa Lucía, cedidos por el rey navarro Sancho el Fuerte. Diversas fuentes señalan un incendio de 1240 que motivó la refección del conjunto, seguidas por las reconstrucciones del siglo XVI. De todo ello nada queda en pie, arrasado por los avatares del siglo XIX ${ }^{38}$. Pero antes, al completarse la ampliación del barrio o puebla, alargando las calles Herrería y Zapatería, las cercas de la villa quedaban muy próximas a la cabecera de la iglesia conventual, de una sola nave pero de gran porte. Las huertas del convento eran regadas por el Zapardiel, y aguas abajo podían faenar los curtidores y las tenerías. En cambio, desde el ángulo sudoeste de la nueva puebla, frente al gran espacio que posteriormente será plaza del mercado, se iniciaba el camino real hacia Castilla, que dejaba al lado izquierdo el Convento de Santa Clara, de Franciscanas, y al derecho las tapias del Hospital de La Magdalena.

Previa o contemporánea al poblamiento de toda la ladera del levante, tuvo lugar la fundación del Convento de San Francisco, de arraigada implantación y muy influyente en la vida de la villa. Habría sido el mismo poverello San Francisco quien en 1214, peregrinando a Compostela, lo fundase. El núcleo más antiguo del convento, su pequeña iglesia inicial, se situaría enfrente de la boca de entrada a la calle Pintorería, a menos de 50 metros hacia el sur. Ya lo cita un documento de $1248^{39}$. Pronto se amplió, gracias a la cesión en 1270 de nuevos terrenos por parte de la villa, y al padrinazgo de familias nobles, como una nieta del rey Alfonso IX de León, Doña Berenguela López, que dejó en 1296 un rico legado para concluir la iglesia. Así, a fines del siglo XIII se completaban las dependencias conventuales y, un siglo más tarde, su hermosa iglesia dotada de una espaciosa nave y ricas capillas ${ }^{40}$. Georges Jehel recuerda que en esta época son las iglesias conventuales de franciscanos y dominicos quienes atraían particularmente las

38. APRAIZ BUESA, Emilio de, "San Francisco y Santo Domingo. Conventos desaparecidos", en PORTILLA VITORIA, Micaela J. (et alii), Catálogo Monumental.., vol. III, Vitoria, 1971, pp. 301-318.

39. VICTORIA, Fray Juan de, Nobiliario alavés, libro $2^{\circ}$, cap. $1^{\circ}$, f. 168-170, p.207-208: La primera iglesia que los franciscos hubieron en Vitoria fue donde ahora es la capilla de la Magdalena ya dicha, y conforme a aquel tiempo eran como sacello, oratorio y ermita, porque el predicar era fuera y aún el misar en concurso de gente. Y precisa más: el recinto estaba en el sitio donde ahora es la capilla de la Magdalena, al lado de la capilla mayor, a la parte del evangelio. LANDAZURI, José Joaquin de, Suplemento XIX, en Obras históricas sobre la provincia de Alava, t. IV, p.193: Según constaba en el archivo del convento de San Francisco cita un antiguo documento firmado en Vitoria, el año 1248, por el cual Angevin el Carnicero vendió a D. Juan Dominguez un Quiñon de rendimiento, es decir un terreno agrícola situado sobre los Uertos de parte del Mercado cerca Sant Francisco.

40. APRAIZ BUESA, "San Francisco y Santo Domingo", pp. 304-310. 
sepulturas de los grandes personajes. En el caso de Vitoria, para evitar conflictos, llegaron al menos los dominicos a concertar la entrega de una cantidad a los cabildos de la universidad de parroquias ${ }^{41}$. Por otro lado, se ha valorado mucho la sugerente idea del historiador Jacques Le Goff de evaluar el desarrollo urbano mediante el cómputo del número de frailes que había en una ciudad, puesto que el olfato apostólico o la sabia estrategia de los frailes les llevaba a instalarse en las ciudades más prometedoras ${ }^{42}$.

Mirando su ubicación y la supuesta fecha de 1214 en que inició su implantación, en la primera mitad del siglo XIII, cuando aún se supone que estaba vacante el gran espacio de ladera que ocupará la futura puebla del este, parece sorprendente que el convento se viera desplazado hacia el lado izquierdo, más bajo, del camino en rampa que daba acceso a la villa, y no se asentase en el lado derecho y más elevado, donde quedará así espacio libre para la planificación de la nueva puebla oriental. Pero sin duda fue la cesión de la parcela concreta lo que determinó su ubicación, por otra parte muy estratégica, como en el extremo opuesto de la villa el convento dominico, pues entre ambas controlaban los dos accesos más frecuentados de la villa.

Respecto a la Puebla nueva del Este el mecenazgo será atribuido a otro monarca.

El historiador Landázuri recoge la noticia de la fundación por Alfonso X el Sabio de Castilla: mandé edificar en la Puebla nueva de fuera una iglesia en vocacion de San Illefonso..., concretando el inicio de las obras de tal iglesia en 1256, durante la estancia del rey en Vitoria, y explica la dedicación a San Ildefonso por devoción que tenía a este Gran Santo Arzobispo de Toledo, que por otro lado coincidía con su nombre propio. Supone, por un documento de 1257, que ya estaba terminada en ese mismo año, pero esta información debe corregirse ampliando las posibilidades de continuación hasta otro documento de 1270 , en que se afirma que quedaba concluida, siendo ese un plazo más normal para una iglesia de tres naves y crucero $^{43}$.

Esta iniciativa pionera del rey sabio en San Ildefonso refuerza los argumentos que han asignado al mismo rey el impulso de poblamiento y expansión urbana de la nueva barriada que surgía por el este ${ }^{44}$. Constan varias estancias

41. JEHEL,...; RACINET,..., La Ciudad Medieval, p.150. VICTORIA, Nobiliario alavés, libro $2^{\circ}$, cap. 17, f. 238 v ss, p. 257-258.

42. Citado por MONSALVO ANTÓN, Las ciudades europeas, p. 24 y 107.

43. LANDAZURI, "Historia civil,..." t. I, p.136.

44. FLORANES: Memorias y Privilegios, 1775, vol 6, Madrid, 1922, p.39: Otra tanta población como hizo Dn Alonso el VIII en la caída de la Villa de suso al Occidente, mandó fundar Dn Alonso el Sabio hacia el Oriente, y por el mismo método de tres calles cerradas con sus puertas a mediodía y Norte. Y consta que en el año de 1256, en que estuvo en Vitoria (...), fundó en aquel barrio la Iglesia de San Ildefonso, con el designio de que sirviese de Parroquia a esta nueva población... 
de Alfonso X el Sabio en Vitoria, una desde fines de 1255, a comienzos de 1256, para vigilar de cerca las osadas maniobras de D. Lope Díaz de Haro, y momento en que firma y emite el fuero de Salvatierra sobre la aldea previa de Hagurhain. Una segunda estancia, también motivada por semejantes revueltas nobiliarias, se concreta en 1270 . Y la tercera, que parece de larga duración, ocurrió entre 1276 y 1277. De varios sucesos ocurridos en tales visitas, como la enfermedad y prodigiosa curación del rey, nos informan las Cantigas.

Respecto a la parroquia de San Ildefonso, no todos los informantes coinciden en atribuir a su fundación a Alfonso X el Sabio, puesto que, como ya recuerda Floranes, desde antiguo surgió una confusión dado que se cambiaba su nombre por el de Alfonso XI, el que realizó la concordia con los alaveses en 1332. Los datos abonan que fue el Sabio quien la fundó, según un dato no fácil de confirmar, sobre su propio palacio en 1256. Esta tradición fue también recogida en el siglo XVI por fray Juan de Victoria, que, aunque es de los que se inclinaban por Alfonso XI, en vez de por el rey Sabio, señala: de la data que hizo de su casa para que allí se fundase la iglesia de San Ildefonso que hoy es ${ }^{45}$.

Determinó, conforme a su propio nombre de pila, que la advocación fuera la del santo toledano su homónimo: Ildefonso = Alfonso (en latín Adefonsus), cuya fiesta es el 23 de enero. Tenía tres naves y crucero. Retomando a Fray Juan de Victoria, vemos que recuerda que sus bóvedas y arcos habían sido construidos de madera pintada, imitando los sillares de piedra ${ }^{46}$, pero que luego Juan López de Arrieta las fue construyendo de piedra. Quizá ocurrió en esta iglesia como en Santa María, cuyos muros no estaban construidos para soportar el peso y las presiones del abovedamiento de piedra, sino de madera, por lo que la nave central y el equilibrio general se han visto del todo comprometidos en su estabilidad. A Santa María le está salvando la gran operación de consolidación y restauración en la que se halla abierta por obras, pero a San Ildefonso, en el siglo XIX no le pudo salvar, y en vez de afrontar su reparación se decidió su derribo en 1839 para aprovechar la piedra en los bastiones de defensa de la ciudad, amenazada en la primera guerra carlista.

El patrocinio del rey Sabio castellano se plasmó en una impactante imagen de bulto del mismo rey Alfonso X con su cetro, colocada en lugar honorífico. La efigie real, según fray Juan de Victoria estaría en lo alto de la capilla mayor sobre el retablo, y según Floranes en la nave de la Epístola ${ }^{47}$, es decir en el lateral del sur, presumiblemente en este caso junto a una entrada de la iglesia ${ }^{48}$.

45. VICTORIA, Nobiliario alavés, libro $1^{\circ}$, cap. 11, f.61-62, p.53.

46. Todo pintado y canteado de colorado. VICTORIA, Nobiliario alavés, libro $2^{\circ}$, cap. 1 , f.168 ss, p. 209.

47. FLORANES: Memorias y Privilegios, p.40.

48. Nos viene a la memoria la conocida estatua, que siguiendo a Bertaux, se cree representa al rey Alfonso X el Sabio, erguido sobre su peana en el claustro de la catedral de Burgos, 
En el área ocupada por la nueva puebla del este, constatamos la temprana instalación de una torre defensiva con su foso. Se trata de una de las típicas casas-torres, como las construidas entre los siglos XIII y XIV, con foso, pozo y fuertes muros, pero fue embutida posteriormente en una casa palaciega, conocida como la Casa del Cordón ya que orna su fachada este emblema franciscano. Esta Casa conoció un particular momento de gloria en 1522, puesto que en ella residía el Cardenal Adriano de Utrecht, regente de Carlos I (o Carlos V) durante la guerra de las Comunidades, y es allí donde recibirá el anuncio de su elevación al Pontificado.

Es sorprendente la similitud en el trazado de las calles de esta área con la puebla del oeste, marcando simetría lateral completa. Hay al menos alguna verificación del trazado exterior de las Cercas, cuyos fundamentos la arqueología ha llegado a encontrar en la manzana de casas de la calle actual de nueva de fuera que quedaba al sur, en el borde de la villa, muy cerca de la Puente del Rey, con su portal, que populariza este nombre desde la entrada de Carlos V en 1524.

Siempre ha quedado memoria de que una parte de la población de la nueva barriada seguía con ocupaciones agrarias. Pero se acompañaba de la dedicación artesanal, tal como parecen asegurar los nombres de sus calles: Cuchillería la más alta, Pintorería la segunda. No resulta extraño el gremio de los cuchilleros o armeros en Vitoria, dadas las referencias desde poco después del año 1000, en la abundante entrega de rejas de hierro a San Millán, a la perduración de ferrerías, a la constante importación de mineral desde Vizcaya o Guipúzcoa. Hay testimonios del gran aprecio de estas armas y de los variados instrumentos de corte fabricados en la villa vitoriana. Para las pequeñas fraguas o forjas, a diferencia de las ferrerías, no es tan necesaria el agua abundante y corriente.

Consta aún la existencia de pozos o aljibes en la zona, que quizá constituyeran una base de provisión de ese elemento. A ese respecto he podido constatar, gracias a seguir de cerca las excavaciones arqueológicas, la existencia de algunos pozos en la primera vecindad ${ }^{49}$. Pero una prospección sistemática aportaría muchos más, pese a los que se han cegado del todo y ya resultan imposibles de descubrir.

En cuanto a la calle de la Pintorería, puede quizá englobar a variados oficios de la construcción, como la albañilería o cantería. Pensemos primero en los que se dedican a blanquear o encalar muros para proteger, por dentro y fuera, las

\footnotetext{
haciendo pendant a la bella estatua de su esposa Doña Violante a quien le ofrece un anillo como signo de su voto matrimonial, aunque el historiador del arte Krange cree reconocer a Fernando III el Santo con su esposa Beatriz de Suabia. No hay duda de su filiación gótica, y de que constituye uno de los más expresivos conjuntos estatuarios de las últimas décadas del siglo XIII.

49. Se localizan pozos en los números 18 y 24 de la calle Cuchillería, este segundo está en la Casa del Cordón y será el pozo más conocido de toda la calle. Otro pozo en la segunda vecindad de esta calle, en este caso a la mano izquierda, en el número 41.
} 
superficies, ocultando así los materiales pobres con que se construía, oficio próximo a los de albañil y carpintero. No podemos olvidar a los artesanos especializados en labores decorativas a base de color y auténticos pintores, que desde la fase gótica al menos, tenían encargos múltiples a raíz de la construcción de tantas iglesias rurales, y tarea también posible de parte de algunas pocas, pero más pudientes iglesias parroquiales o conventuales de la villa. Las muestras de superficies pintadas en iglesias alavesas crecen de año en año, en particular gracias a la ingente labor de restauración emprendida mancomunadamente por responsables de la Diputación Foral de Álava y el Obispado de Vitoria. Hay iglesias simplemente pinceladas con la ficción de sillares cuadriculados, tal como gráficamente lo define Fray Juan de Victoria pintado y canteado de colorado ${ }^{50}$ pero otras reciben un desarrollo de escenas y temas iconográficos, en ocasiones de mucha calidad. Un ejemplo de pintura mural gótica que aún puede verse dentro del territorio jurisdiccional de la ciudad de Vitoria es el de la iglesia de San Martín de Avendaño.

En la documentación de archivo local no son raras las alusiones a pintores. En algún caso llegan a especificar la tarea de los que complementaban con color la imaginería religiosa. El 30 de abril de 1428 los administradores del concejo de Vitoria entregaban al pintor Juan Martines 900 maravedíes por tres ymagenes que fase de Fabyan et de Sebastian e de Santa Anastasia para en la iglesia de Sant Miguell de Bitoria ${ }^{51}$.

En ese desarrollo urbano cuenta mucho el factor de atracción de poblaciones alógenas, y entre ellas forma un grupo particular el formado por judíos, con sus características no sólo étnicas sino religiosas y de dedicación económica que los singularizan. Podemos pensar que pronto llegó un grupo pionero y luego la comunidad se densificó, de manera que, hacia mediados del siglo XIII, ya tenían suficiente entidad como para que sean citados en las listas de contribución de los clérigos de la Diócesis de Calahorra (las rentas procedentes de un grupo se destinarían a la mesa episcopal y las del otro al Cabildo diocesano), elaborada bajo el mandato del obispo D. Jerónimo Aznar (1238-1257) en 1257. Así, en el arciprestazgo de Victoria, detrás de Argandoña, en el último lugar de contribución a la mesa episcopal, se indica: E los judios de Victoria ${ }^{52} \ldots$

Este dato no ha sido muy tenido en cuenta por quienes han atribuido la Ilegada a Vitoria de los judíos, a un patrocinio del rey Alfonso X el Sabio, reinante desde 1252, pues si la iniciativa real en Vitoria despega con claridad en

50. Ver nota 46.

51. DÍAZ DE DURANA, J.R.; Vitoria a fines de la Edad Media. 1428-1476, p.269.

52. El documento del obispo D. Jerónimo Aznar es transcrito por los historiadores locales, en algún caso con muchas erratas. Nos basamos en la lectura de CARO BAROJA, Julio: Alava en la llamada "Reja de San Millán», T.III 1983, pp.141-148, con la referencia concreta en p.143. El manuscrito calagurritano se halla en la Biblioteca Nacional de Madrid, $\mathrm{n}^{\circ} 704$. 


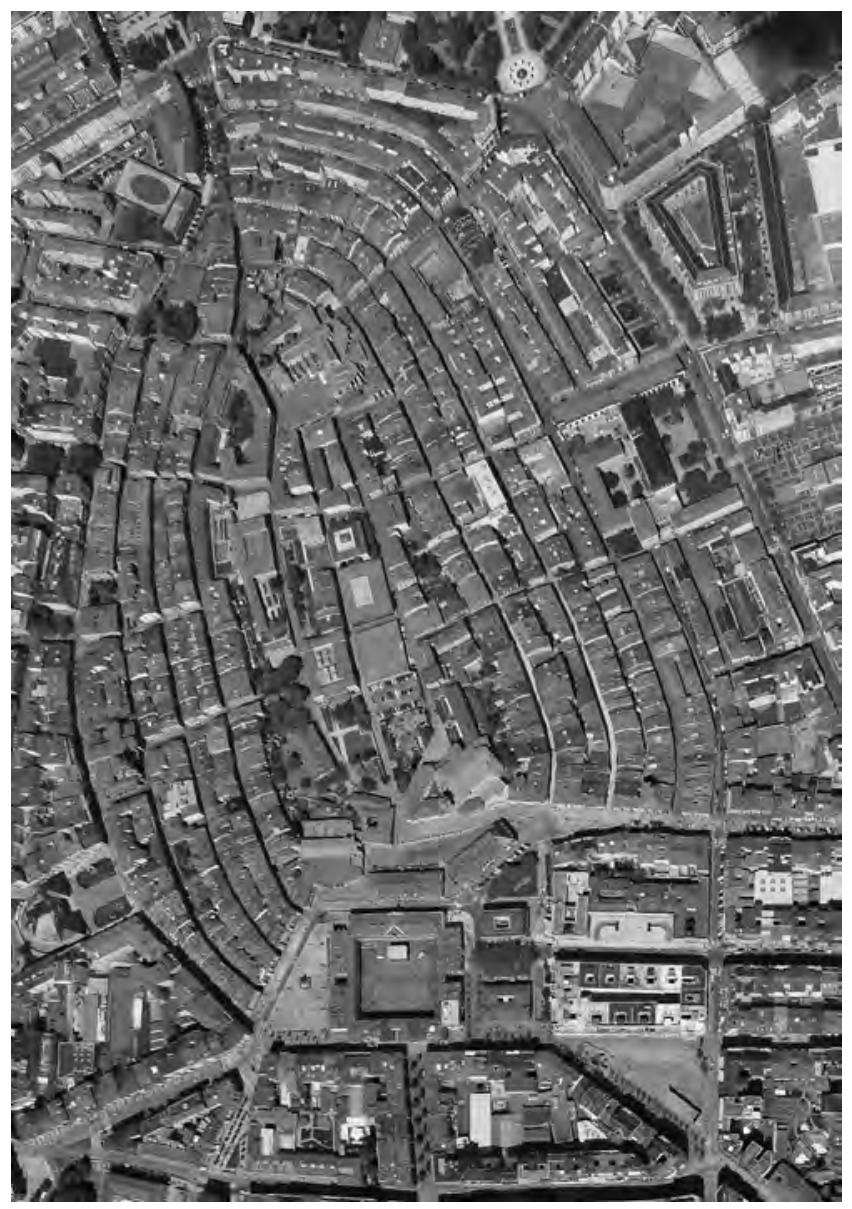

Figura 5: La vista en picado descubre los matices de la planificación sucesiva: el núcleo ovalado en Villa Suso y el trazado concéntrico envolvente de las dos barriadas laterales. FOAT.

1256, y el dato sobre contribución de los judíos es de 1257, no parece normal que se llegase a imponer tal carga a un colectivo que apenas ha podido instalarse o que no es aún significativo ${ }^{53}$.

53. Haciendo referencia a un documento de 1276, señala Floranes: ... Los Judíos... debieron arrivar a Vitoria luego que Don Alonso el Sabio acabó de fundar aquella población y acaso él 
La comunidad judía se había instalado en la extremidad sudoriental de la villa. Allí construyeron una sinagoga, y para su administración propia elegían un Juez y un Procurador y un Regidor ${ }^{54}$. La calle Judería, al ser abandonada cuando se produzca la expulsión, decretada en 1492, será llamada calle nueva. Se precisará aún más, denominándola calle nueva de dentro, cuando el exterior de la muralla adopte en ese lugar forma de calle por la construcción de casas enfrente. Según un dato que aporta Floranes, el ángulo extremo de la muralla baja, junto a la Judería, estaba reforzado con un fuerte torreón ${ }^{55}$. La muralla baja servirá de dique de contención o es la medida de capacidad urbana, más o menos compactada de la villa, durante varios siglos, englobando en total un recinto de casi 21 Hectáreas.

\section{Las murallas, puertas y caminos}

En el lejano horizonte cultural de occidente siempre está la sombra de Roma. Perduraba su fama de expertos en poliorcética, en la construcción de campamentos y de oppida. Si recurrimos a las Etimologías del recopilador San Isidoro, vemos que no es muy elocuente en este punto y se contenta con ir a la etimología: Las murallas son las cercas de las ciudades, así llamadas porque protegen a la ciudad, como fortificaciones o defensas ${ }^{56}$. Al menos los consejos de Vitruvio resultaban prácticos y, por tanto, pertinentes: La forma de una plaza fuerte no debe ser ni cuadrada ni de ángulos agudos, sino circular, para que el enemigo pueda ser divisado desde varios puntos. Insiste en la importancia de espaciar fuertes torres, cuyas distancias se han de fijar de manera que no estén separadas una de otra más de un tiro de saeta ${ }^{57} \ldots$

Más rotundo es Alfonso X el Sabio, uno de los principales fundadores y promotores urbanos de Vitoria: a la ciudad la hacen sus murallas ${ }^{58}$. Pero las murallas

mismo los introdujo, porque en su tiempo constan los más antiguos de que hasta aora tenemos noticias en esta Ciudad, y son Don Cag y su hermano Don Jucef, hijos de Almojarif Don Maiz. FLORANES, Memorias y Privilegios, pp.88.

54. FLORANES, Memorias y Privilegios, pp.87.

55. FLORANES Memorias y Privilegios, pp.89: En 1481 se mencionan las casas de la calle de la Judería hacia la torre de la Puente del Rey.

56. ISIDORO DE SEVILLA, Etymologiae, Liber XV, "De civitatibus": Moenia sunt muri civitatis, dicta ab eo quod muniant civitatem, quasi munimenta urbis, id est tutamenta.

57. VITRUVIO, Marco Lucio, Los diez libros de arquitectura, (Lib.I, cap.V), p.22-23.

58. ALFONSO X EL SABIO, Las Partidas, III, Título XXVIII, Ley XV: Santas cosas son Ilamadas los muros et las puertas de las cibdades et de las villas: et por ende establescieron antiguamente los emperadores et los filosofos que ningunt home non los quebrantase rompiendolos nin foradandolos nin entrando sobre ellos por escaleras nin por otra manera ninguna que sea sinon por las puertas tan solamente. 
constituyen a la vez el más grave problema financiero para atender debidamente no sólo a su construcción sino también a su mantenimiento.

La muralla alta de Villa Suso se compone de un aparejo de mampostería, obtenido del entorno, con un tratamiento más cuidado de los esquinales, por ejemplo en las torres, realizadas con mampuestos encintados. Varios datos historiográficos apuntan a que había diecisiete torres en la parte alta, conservándose las estructuras de base en unos cuantos casos, sobre todo en el costado occidental.

Volvemos a la sombra del solar de los Ayala. A través de una genealogía elaborada por Fernán Pérez de Ayala, plasmada en el libro conocido como Arbol de la Casa de Ayala ${ }^{59}$, la familia Ayala presumía de remontarse al conde Don Vela, hijo bastardo del rey de Aragón, que afianzó en Alava el tronco de los Ayala, y que supuestamente habría labrado la muralla de Vitoria hacia fines del siglo XI, lo que de momento parece coincidir con los últimos hallazgos arqueológicos. En realidad no parece que los cronistas medievales ni los genealogistas de la casa de Ayala han divulgado un dato que hubiera sido muy prestigioso. No vemos alusiones a ello ni en las Bienandanzas e Fortunas de Lope García de Salazar ni en Fray Juan de Victoria, pese a que se ocupan en particular de esa familia.

Con la expansión del siglo XIII, todo el perímetro que comprendía las dos nuevas pueblas quedaba amurallado, con las Ilamadas a veces Cercas Altas, pues al menos en la zona del poniente se ha mantenido el recuerdo de las Cercas Bajas, señalando un doble cordón defensivo, el segundo de extensión parcial. El arroyo Zapardiel dificultaba, según queda dicho, un posible ataque a estas Cercas Altas, y algo similar ocurría en el extremo opuesto con el arroyo de los Molinos, desviado para servir de barrera al pie del muro. Pero hay alusiones en las descripciones antiguas a puentes que salvaban cavas incluso en el gran espacio abierto en ambas laderas al sur, donde desembocan las seis calles gremiales de ambas pueblas. Como hemos recordado, Floranes cita junto a la Judería la torre de la Puente del rey ${ }^{60}$. Ello podía aumentar la capacidad defensiva. Una muy reciente excavación arqueológica, practicada con ocasión de remodelar la plaza de la Virgen Blanca, ha sacado a la luz uno de estos sencillos puentes, de más de 8 metros de longitud, frente a la entrada de la calle Zapatería, sobre una torrentera que bajaba aprovechando una zanja excavada a la manera de un modesto foso ${ }^{61}$. Podemos señalar que también en esa

59. Llamado mejor: "Libro del linaje de los Señores de Ayala desde el primero que se llamó Don Vela hasta mí Don Fernan Perez", fechado en 1371 y cuya mejor copia se conserva en la Real Academia de Madrid.

60. FLORANES: Memorias y Privilegios, p.89.

61. CABRERIZO BENITO, Kepa; CARDOSO TOSTADO, José, Aproximación al doblamiento de Vitoria-Gasteiz a través de sus excavaciones en la plaza de la Virgen Blanca, en "Estudios de Arqueología Alavesa", n² 24, Vitoria, 2009, pp. 401-417. 
zona descubrieron algunas cerámicas romanas y los testimonios de restos de habitación en el siglo VII.

En Villa Suso, la puerta principal desde la antigüedad fue la de San Bartolomé, en la proa del navío o espolón sur de la colina ${ }^{62}$, junto a San Miguel, donde debe situarse el medianetum o lugar neutral para los juicios, tal como se indicaba en el fuero de población de 1181. En el extremo opuesto, al norte habría otra puerta, quizá dedicada a Santa María, como la iglesia allí situada. Es menos clara la ubicación de puertas en los lienzos largos de muralla, al menos hasta que la arqueología logre un control de evidencias en el subsuelo. Lo más probable es que inicialmente sólo hubiera una por el oeste, en la zona del tradicional cantón de la Soledad, y pudieron ser por el este sólo dos: las de los cantones de San Marcos, y de Santa Ana. Pero en un momento posterior se abrió una más por cada costado, tal como señala Landázuríi3.

En cuanto a las puertas de la muralla baja, suele hablarse de 14 puertas, todas ellas muy bien guarnecidas, lo que recuerdan de manera insistente Fray Juan de Victoria y $\operatorname{otros}^{64}$, de modo que, haciendo un giro en sentido contrario a las agujas del reloj desde el sur, tenemos las bocas de las calles Cuchillería, Pintorería, Judería o calle Nueva Dentro, portal del Colegio, portal de San Ildefonso, portal de Urbina, portal del Barrancal y Santo Domingo, portal de Arriaga, portal de Aldabe, portal Oscuro o de Angebín ${ }^{65}$, San Pedro y, doblando por la plaza del Mercado, las bocas de las calles Herrería, Zapatería y Correría.

Desde la Baja Edad Media, las más poderosas familias señoriales se instalaron con torres y castilletes sobre las puertas, de manera que la ciudad les confiaba su defensa y ellos se beneficiaban del prestigio y de la seguridad particular de tal posición de fuerza ${ }^{66}$. En Villa Suso, el palacio fortificado de los Ayala, sobre el portal principal de San Bartolomé, junto al antiguo castillo de San Vicente, los

62. De ello ofrece información directa Fray Juan de Victoria: y las puertas de Villa Suso con sus revueltas y castilletes que se han quitado poco a poco desde que Navarra ha entrado en la corona de Castilla, año de 1512. VICTORIA, Nobiliario alavés, lib. $1^{\circ}$, cap. 7, f. 51 v ss, p.37.

63. LANDAZURI, "Ciudad de Vitoria", en Obras históricas sobre la provincia de Alava, t. I, p.3.

64. Un testigo directo, Fray Juan de Victoria lo recuerda: El rey don Sancho el Fuerte... fortificó a Vitoria en sus puertas y calles. Y muchos alcanzamos [a ver] en las puertas de las calles, a una banda y otra, las trampas y las puertas levadizas y las puertas muy gruesas y guarnecidas con vigones, barras de hierro y clavazón y gruesas cadenas..., VICTORIA, Nobiliario alavés, lib. $1^{\circ}$, cap. 7 , f. 51 v ss, p. 37.

65. Tiempo después se llamará cantón o portal de Anorbín, por mal entendimiento, al que había popularizado Angebín de Maturana, personaje vitoriano muy activo a lo largo del siglo XV.

66. Landázuri cita a don Diego de Salvatierra, autor del siglo XVI, y su obra Gobierno y Republica de Vitoria: tenían también las bocas de las calles que salen a la plaza mayor, y a la de Santo Domingo, y Santa María, casas fuertes a una vanda, con Alcaldes en ellas, que eran Cavalleros cuyas eran las casas, por los quales entonces el pueblo se regia, no admitiendo al gobierno sino gente noble, de la qual no habia poca. LANDAZURI, "Ciudad de Vitoria", t. I, p.11. 
Salazares, parientes de los Ayala, sobre la puerta de Santa María, en el otro extremo, algo más abajo la torre fuerte de los Anda. Descendiendo al segundo recinto amurallado, sobre la boca de la Cuchillería: los Guevara, luego los Sotos y los Alava; en la Pintorería, los Hurtado de Mendoza; en la boca de la Judería o calle Nueva Dentro, los Landa; en el portal de San Ildefonso, los Larrinzar; en los portalillos del Barrancal, los Abecia y Sarría; en el de Santo Domingo, los Mendoza, como también en el portal de Arriaga; en el portal de Aldabe, los Iruña y los Colodro; en el portal Oscuro y en el de San Pedro, los Maturana - fue uno de los más conocidos Angebín de Maturana, por lo que aún se le llama, con nombre algo modificado: Cantón de Anorbín -; en las bocas de las calles Herrería, los Avendaño y los Alava; en la boca de la Zapatería, los Hurtado de Mendoza, los Maturana, y los Soto; por fin en la boca de la Correría, los Doypa y los Nanclares ${ }^{67}$.

Respecto a la emblemática de símbolos o escudos que, sobre todo en las puertas de la villa, podían existir en época navarra, debemos recurrir una vez más a datos suministrados por fray Juan de Victoria: Puso este rey [Sancho el Sabio] las armas que entonces usaba Navarra en las puertas de estas iglesias y monasterio y ciudad, que era la Anunciación de Nuestra Señora, jarra y azucenas, como aún duran, y en las puertas de la ciudad a San Jorge armado a caballo, a quien apellidan en las batallas los navarros. Después que Vitoria y Alava se dio a la corona de Castilla [...] se ha ido quitando estos san jorges y poniendo los castillos y leones de Castilla ${ }^{68}$.

Según un dato recogido en un momento ya avanzado, pero que proviene de las más viejas costumbres, todas las puertas eran cerradas al ordenarse el toque de queda. Para ello se alertaba a cuantos aún trabajaban en las cercanías con algún repique de campanas. Las puertas quedaban cerradas y vigiladas, con un horario que en invierno podía abarcar desde las ocho de la tarde hasta las seis de la mañana, y podía abreviarse por la mayor luz y para facilitar las faenas veraniegas, desde las nueve de la tarde sólo hasta las cuatro o las cinco de la madrugada.

Lógicamente, como ya ocurría en la Roma clásica con sus famosas vías, las puertas principales están mostrando la salida hacia los destinos más habituales, por los caminos más transitados. Los más concurridos y probablemente más antiguos son los siguientes. En dirección Sur dos ramificaciones: con inclinación al Sudoeste el camino real hacia Castilla (como la N-1 actual), por Gomecha y La Puebla de Arganzón hacia Miranda y Burgos, la otra directamente al Sur el

67. PORTILlA VITORIA, Micaela J., Torres y Casas Fuertes en Alava, 2 vol., ed. Caja de Ahorros Municipal de la Ciudad de Vitoria, Vitoria, 1978 (en particular el t.ll, p.1051-1080). DÍAZ DE DURANA ORTIZ DE URBINA, Alava en la Baja Edad Media..., 1986.

68. VICTORIA, Nobiliario alavés, cap. $7^{\circ}$, p.36. APRAIZ, Ricardo de: La muralla del primitivo Vitoria, en Boletín de la R.S.B. de Amigos del País, año 9, cuad.2, Vitoria, 1953. 
camino hacia la Rioja (como la A-2124), por Arechavaleta y puerto de Vitoria, cruzando Treviño hacia Laguardia y Logroño. Hacia el Norte también dos ramificaciones: con inclinación al Noroeste (como la N-622) el camino por Altube hacia Bilbao y la costa; otro directamente al septentrión (como la N-240) por puertos de montaña hacia Arratia y Durango o hacia el valle guipuzcoano de Léniz, pudiendo en ambos casos transitar hacia localidades de la costa. Por fin una importante ruta hacia el Este, camino de Salvatierra (como la actual N-1), con dirección prioritaria hacia Pamplona o zonas de Navarra, pero pudiendo también doblar hacia Irún y Francia.

\section{Las iglesias medievales}

Las iglesias quedan perfectamente espaciadas ocupando exactamente los cuatro puntos cardinales ${ }^{69}$. La decana Santa María, luego Colegiata y Catedral, asentada en la popa de septentrión del navío fundacional. Mientras, en completa oposición, la proa meridional es ocupada por San Miguel, la antigua iglesia privilegiada como juradera, vecina de la mole de San Vicente, antiguo castillo ${ }^{70}$. El costado de la puebla del poniente, sobre el arroyo Zapardiel, es reforzado por el murallón de San Pedro y, en el costado opuesto, de la puebla de levante, se alzaba en 1257 el nuevo templo de San Ildefonso, de fundación real bajo el patrocinio de Alfonso X el Sabio ${ }^{71}$.

De hecho, la que desde 1862 puede titularse Catedral de Santa María, previamente había sido colegiata y antes parroquia, edificada sobre otra iglesia más antigua, de dimensiones más cortas y de orientación diferente, en giro hacia el sudeste. La obra actual se inició en el siglo XIII, para completarse en su trazado a lo largo del siglo XIV y cubrirse de bóvedas de piedra en el XV, no lejos de la fecha de 1498, en que, según lo dicho, fue elevada a la categoría de Colegiata ${ }^{72}$.

69. Un resumen sobre ellas y algunos datos sobre los clérigos que las servían, en LÓPEZ DE OCÁRIZ ALZOLA, José Javier, "Historia de Vitoria medieval y su topografía urbana", en Construcción de la ciudad. II encuentro hispano-cubano de Arquitectura y Urbanismo, La Habana, 2009, pp.155-157.

70. San Vicente, diácono y mártir de Zaragoza en el siglo IV será uno de los santos más venerados en la Antigüedad tardía, gracias a los panegíricos de San Agustín, San León Magno, San Ambrosio, y sobre todo del poeta Prudencio que le dedica el $5^{\circ}$ poema de su Peristephanon. Su fiesta se calenda el 22 de enero desde los más antiguos Sacramentarios, como el Gregoriano, o el Santoral Visigodo, y está entre las advocaciones más frecuentes de la diócesis de Vitoria, con 13 parroquias aún en pie y algunas ermitas, aunque hay testimonios de más de 40 lugares de culto con tal dedicación.

71. VICTORIA, Nobiliario alavés, lib. $2^{\circ}$, cap. 17, f. 238 v ss, p. 260: Eran las iglesias oratorios y no lugar de entierros como ahora, por lo cual las iglesias que había se han ampliado y multiplicado.

72. PORTILLA VITORIA, Micaela J. Catálogo Monumental... Ciudad de Vitoria, vol. III, 1971. PORTILLA, Micaela J., El arte en los templos vitorianos, en Vitoria, 800 años, nº 8, ed. Caja 
La estructura sigue la tradición cisterciense, de tres naves y un crucero muy desarrollado, en cuyos brazos se practican dos capillas por cada lado, que flanquean la capilla mayor, circundada por la girola que conecta con las tres capiIlas poligonales. El alzado interior, con influencias del gótico francés, es sobrio pero elegante, gracias a la disposición del fino triforio tetralobulado. Podemos pensar que, para su construcción, la fecha de 1387 es un hito. Es entonces cuando se describe la iglesia de Santa María como solemnis et pulchra (solemne y hermosa), proponiéndola como digna para albergar la Colegiata en lugar de la vieja iglesia de Armentia. A falta de otros documentos coetáneos, tal expresión solemnis et pulchra, nos invita a pensar que, ya entonces, estaba concluida al menos en el trazado fundamental, aunque más tarde pudiera ser ampliada, o que sus bóvedas, que provisionalmente eran de madera pintada, se rematasen en piedra.

Consta que esta iglesia de Santa María siempre ejerció como iglesia matriz de la villa, aunque San Miguel fuera la iglesia juradera, y que, desde la Carta de Población de 1181, ambas figuran como acogidas al patronato Real. Pero en la Edad Media no pretendía aún servir como catedral, de manera que no necesitaba claustro ni dependencias episcopales, aunque, frente a ella y dando vista a la plaza, vivieron los clérigos del cabildo. Se rodeó de hospital y cementerio. Su importancia cuenta no sólo por el empaque de una parroquia con aires de catedral, sino también por cubrir la función defensiva en un punto delicado de la villa. Este factor ha obligado a revestir su aspecto exterior con la robustez y la cerrazón de sus muros, en contra del espíritu de apertura de vanos y de la ligereza, propios de la arquitectura gótica. En cambio, esos caracteres siguen presentes en la estructura interna, pese a la parquedad de sus ventanales, gracias a sus gráciles arquerías, y al bello triforio calado.

Quien diseñó el trazado actual de la iglesia de Santa María se veía forzado por un marcado determinante espacial. Una ampliación de la iglesia vieja se topaba con la falta de espacio, pues ya se alcanzaba por el norte y este el límite de la colina, en un punto de fuertes escarpes. Además, ese borde abrupto era el lugar propicio para la línea de muralla. Sin poder aún precisar cómo surge la interacción entre iglesia y muralla, un destino coincidente les obliga a coexistir y a adaptarse ambas en su trazado. Al final la ampliación de la iglesia vuela sobre el cortado y para ello robustece enormemente su mole. Todo ello puede contribuir a explicar la gran desigualdad entre el exterior de Santa María, con aspecto de murallón hermético, y el más delicado semblante interior.

El conjunto de las cinco iglesias, como se ha señalado, se dispuso, estratégicamente ubicado, para controlar todos los puntos sensibles de la villa y ciudad.

Provincial de Ahorros de Alava, Vitoria, 1981. PORTILLA, Micaela, Una ruta europea. Por Alava a Compostela, 1991. 
Las razones para ello pudieron ser prácticas: uno, para facilitar un cómodo acceso a los vecinos; dos, castrenses, porque sus moles de piedra contribuían al trazado defensivo en la muralla alta, o en el centro de los costados largos del levante y poniente, teóricamente más frágiles; y tres, incluso razones simbólicas, para cubrir el espacio visible con torres y el aire con sones de campanas. En pocas poblaciones se puede visualizar un organigrama topográfico tan conjuntado con el entramado de calles, puertas y murallas, como el de las cinco parroquias vitorianas en la Edad Media.

Sin espacio para detallar sus cualidades artísticas, al menos cabe comentar que San Pedro y San Miguel, en fase incipiente, y la de San Vicente ya dentro del pleno estilo, muestran un tipo particular de hallenkirche o iglesia - salón, que arraigará de forma muy prolongada en el entorno, lo que permitirá calificar a la corriente como gótico vasco. Poco podemos decir de la quinta parroquia, la que falta, pues la desdicha de las guerras civiles del siglo XIX, fue el pretexto para que fuera derribada en 1839, con la pretensión de aprovechar su buena piedra para reforzar los bastiones defensivos de la ciudad.

\section{La plaza}

No es un marco urbano que podamos definir con precisión en estas etapas antiguas de la formación de la villa. En realidad sólo quedan cortas referencias, como un documento de 1248, que alude a la ubicación del mercado semanal ${ }^{73}$. En el siglo XII pudo iniciarse junto al antiguo cementerio de San Miguel, bajo la puerta principal de San Bartolomé, el lugar mágico del medianetum. Y podemos concluir que, cuando el lugar resultase insuficiente por la ampliación de vendedores y por las ferias, su localización aprovechó, como en los siglos posteriores, la enorme explanada que se extiende al pie de la fachada meridional de San Miguel hasta llegar a desperdigarse, en fechas avanzadas, de manera que pudieran referirse algunas fuentes escritas, al fondón del mercado.

Así la describe en el siglo XVIII el historiador Landázuri, antes de platearse el enorme recorte de terreno para instalar en ella la Plaza Nueva de Olaguíbel: Aunque la plaza de Victoria no tiene aquella forma material que tienen otras que se admiten en diferentes Ciudades del Reyno, no obstante es un Amphiteatro ostentoso. Está rodeado por todas partes de los mas lucidos edificios, no

73. LANDAZURI, en Obras históricas sobre la provincia de Alava, t. IV, p.193. Se ha citado en la nota 39 un documento de 1248 en que Angevin el Carnicero verde a D. Juan Domínguez un Quiñon de rendimiento, es decir un terreno agrícola situado sobre los Uertos de parte del Mercado cerca Sant Francisco de Vitoria. Ello prueba que ya en la primera mitad del siglo XIII, antes de poblarse el barrio oriental de Vitoria, ya se celebraba el mercado, cerca del convento franciscano, en el amplio espacio de la plaza, conocido tradicionalmente como plaza del Mercado, hoy plaza de la Virgen Blanca. 
solamente de casa particulares, sino es tambien de la Consistorial de la Ciudad, y su Alhondiga, Iglesia Parroquial de San Miguel, Convento de San Francisco, Hospital de Santiago, y Real Carcel. Lo magnifico de los edificios, y lo estendido, y espacioso de la plaza de esta Ciudad, dan un golpe de vista el mas agradable à quantos entran en ella, especialmente por la parte del camino Real de Castilla, que es la mas frequentada ${ }^{74}$.

\section{Un trazado regular sucesivo en Vitoria: oval y envolvente}

Partimos de una distinción básica entre la morfología propia de las poblaciones surgidas con un desarrollo espontáneo y las que muestran signos de una planificación urbana. Pero hay un condicionante previo a tener en cuenta. Lo señalaba Pirenne: La formación de las ciudades medievales es un fenómeno casi tan claramente determinado por el medio geográfico y social como lo está el curso de los ríos por el relieve de las montañas y la dirección de los valles ${ }^{75}$. Debemos detenernos en examinar la topografía del emplazamiento, el relieve, los ríos y, en menor medida, los materiales disponibles, incluso el clima. La elección del emplazamiento puede obedecer a razones estratégicas que aconsejen controlar un puerto de mar, el paso de un río, un puerto de montaña, o favorecer la defensa en una eminencia del terreno. En tales casos surgen unos condicionantes espaciales que, cuanto más peso tienen, más limitan la libertad del planificador, cuyos proyectos deberán adaptarse a ellos. Quien quiera libertad de planificación, deberá seleccionar un emplazamiento limpio.

Analizando el conjunto medieval edificado en Vitoria, tal como nos ha llegado, se evidencian unas constantes de simetría, regularidad, orden en las paralelas, y un evidente ajuste en los trazados a unas líneas de geometría esencial. Lo señala Caro Baroja: Pero es la capital (Vitoria), en su parte anterior a los ensanches del siglo XVIII, el modelo más acabado que podamos encontrar de población sujeta a plan ${ }^{76}$. Por tanto, no nos cabe duda de que eso no surge por generación espontánea. Ha sido necesario partir de unos criterios de planificación, y después se ha seguido un proceso de control eficaz de los mismos, y de corrección de cualquier irregularidad.

Sin embargo, nadie podrá pretender que, ya desde 1181, o incluso antes, se pudiera anticipar el trazado global, tal como se veía hacia 1300, con las tres áreas: la superior y las dos laterales, organizadas y pobladas. De alguna

74. LANDAZURI, "Ciudad de Vitoria", en Obras históricas sobre la provincia de Alava, t. I, p.5.

75. PIRENNE, Las ciudades de la Edad Media, p.92. También insiste en algo parecido JEHEL, Georges; RACINET, Philippe, La Ciudad Medieval, p.69: ... la ciudad no es una entidad autónoma, que se desarrolla de manera endógena sin interferencia de su entorno... se define por un asentamiento espacial, un perímetro y un área de extensión...

76. CARO BAROJA, Julio, Los Vascos, Madrid, Istmo, 1971, p.41. 


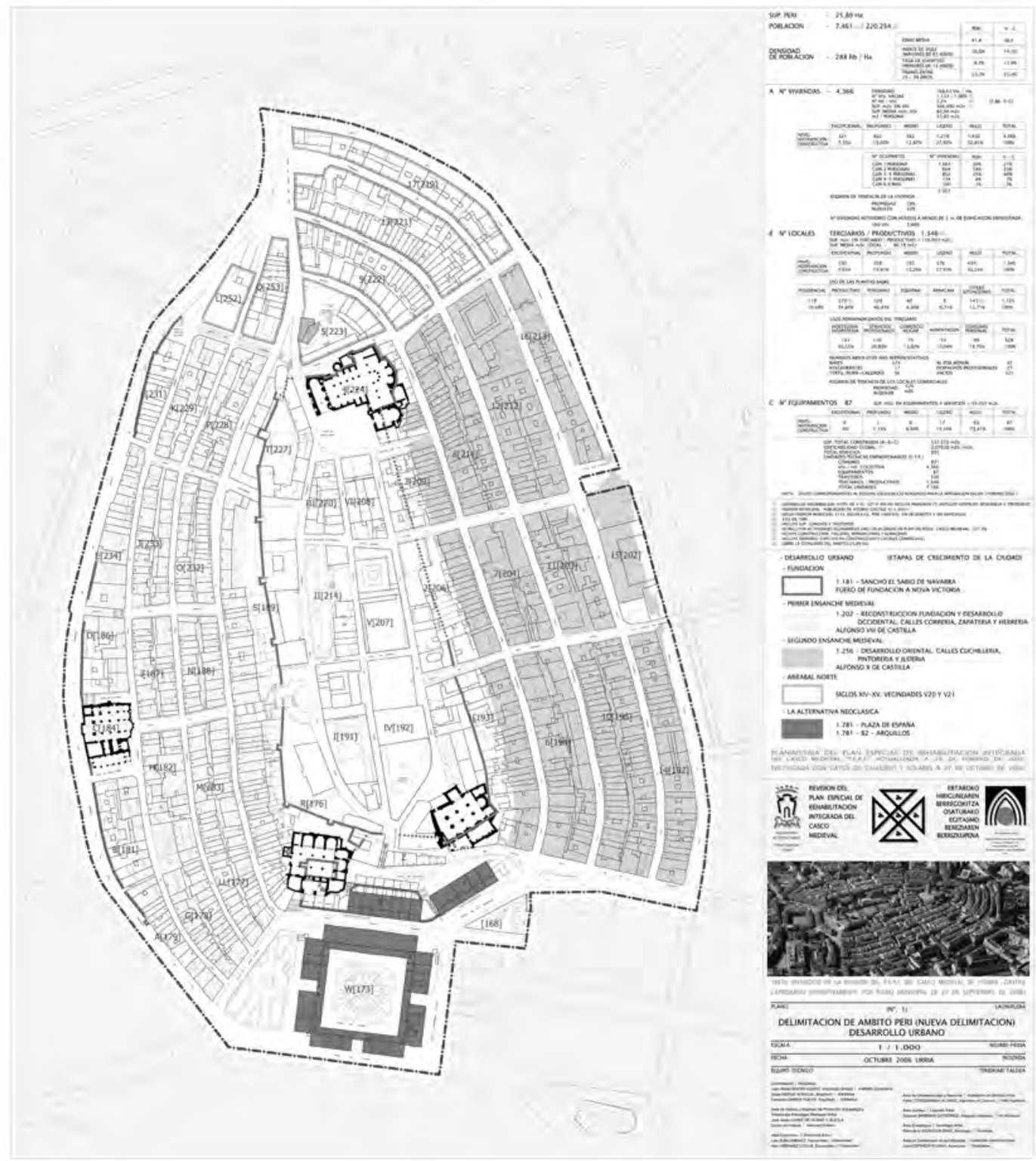

Figura 6: Planimetría del Plan Especial de Rehabilitación Integrada "P.E.R.I." del Casco Medieval de Vitoria (1999-2006), en que hemos colaborado un equipo multidisciplinar (plano $\left.n^{\circ} 1\right)$. 
manera, como se evidencia en el caso de la ciudad de París, aspecto subrayado por algunos urbanistas, como referencia, puede distinguirse, también en Vitoria, y salvando las diferencias, la cité antigua y la ville que la rodea.

Por tanto, debemos en ella hablar de dos proyectos diferentes, el de Villa Suso y el de Villa Yuso, sólo que este último pudo aplicarse, de manera coherente, a dos áreas simétricas, lo que en el desarrollo de fases supone un triple proceso de planificación.

Iniciamos, por tanto, el análisis del área superior, la llamada Villa de Suso y tenemos en cuenta su emplazamiento en la cumbre amesetada de un cerro con forma de huso. Siguiendo fielmente la adaptación a su topografía, el recinto murado se organiza en tres calles longitudinales paralelas, marcando un eje principal recto: la calle central, secundada a los lados por las dos laterales que, en ambos extremos, se curvan de forma convergente hacia el eje, favoreciendo el paso hacia las puertas de los extremos.

Cuestión más aventurada es la de bucear en las posibilidades del origen del plan viario de la colina en la aldea de Gasteiz o en el inicio de la nueva villa. No podemos más que sugerir hipótesis. Podemos imaginar que surgieron alternativamente, o a la vez, dos polos edificados: las antiguas iglesias de Santa María al norte y al sur la de San Miguel, quizá también reforzado con un adicional lugar de culto dedicado a San Vicente ${ }^{77}$. Una senda espontánea de atracción y comunicación entre ambos polos recorre el espinazo de la colina; es un espacio-camino que ni siquiera necesita planificación artificial. Pero, a continuación, será necesario establecer un programa de decisiones puntuales: habrá que ir fijando acuerdos o normativas sucesivas sobre la anchura del vial, sobre la disposición y el tamaño de los lotes para la construcción, en relación a que se dispongan de cara a cada calle-eje unas manzanas simples o dobles, en cuanto a que sus traseras respondan a una línea regular de frente, de modo que permita habilitar sendas calles en los espacios traseros, y también en definir tramos con pequeñas callejas traveseras o cantones.

En cierto sentido, la senda espontánea axial del espinazo de Gasteiz enlaza con todos los trazados de villas que responden a la denominación de villas o ciudades-camino. Si es claro que, en los más típicos ejemplos eran sobre todo los caminantes foráneos: francos, comerciantes o peregrinos, quienes, en su caminar buscando a veces el paso del puente, determinaron espontáneamente el trazado de la calle, en Gasteiz lo fue de manera más doméstica, pero con la

77. Gráficamente recalca Fray Juan de Victoria la polaridad de las dos iglesias en ambos cornisales: El rey don Sancho el valiente y Sabio de Navarra, cuando fundó la villa de Suso, que Ilamó en su privilegio su Nueva Victoria, fundó también en sus dos cabezas o cornisales, o en su cabeza y pies, o proa y popa, dos iglesias fuertes, hechas fortalezas con sus almenas, torres, andenes dentro y fuera, como hoy se ven en Santa María que era la mayor....(luego cita a) la fortaleza de San Vicente. VICTORIA, Nobiliario alavés, lib. 2º, cap. 1, f.168-168 v, p.206. 
misma lógica del trayecto más corto. Aunque el punto de partida no sea el mismo, hay una confluencia en el resultado con la definida como ciudad-lineal o ciudad-camino, que a veces muestra una disposición longitudinal de triple viario, como en Villa Suso. Así se le ha visto relacionada por algunos autores con el trazado de las ciudades itinerantes, como son habituales a lo largo del camino jacobeo, por ejemplo en Estella, Logroño, Santo Domingo de la Calzada y Burgos. Hay casos particularmente significativos, porque no han tenido un crecimiento posterior que enmascarase su trazado, como los casos de Puentelarreina o Sangüesa, ambas de antigua fundación navarra, para facilitar y acoger el paso por el puente de transeúntes y peregrinos ${ }^{78}$.

En realidad, la estructura que agrupa tres calles largas y paralelas, le equipara con muchas villas medievales, unas, las del camino por armonización de dos calles paralelas al eje principal, otras en cambio, forzadas por un espacio alargado y angosto entre sus muros. Los criterios de tal disposición son los de simplicidad y sentido práctico de adaptación espacial. En resumen, el carácter dominante en esta fase primera de Gasteiz-Vitoria, como en muchas villas del entorno, es un plano regular de tres calles paralelas adaptadas a un contorno ovalado, casi elíptico de su topografía. Es el mismo caso de Laguardia, Lapuebla de Arganzón, Labraza o Salvatierra, en comarcas del entorno alavés y de Hernani, Mondragón y Villafranca de Ordizia en Guipúzcoa ${ }^{79}$.

No olvidamos que tanto el ejemplo vitoriano, como los de Laguardia y Salvatierra, van reforzados en su estructura por el perfil elevado sobre colinas y por la potenciación de una fuerte muralla circundante. El aspecto es muy similar al de una acrópolis o villa fortaleza, por lo que también encaja en una de las

78. Ambas poblaciones son ejemplos típicos de la ciudad itinerante. En Puentelarreina, fundada en 1124 como sucesora de la anterior aldea de Gares, es evidente el papel axial de su rúa mayor como prolongación del puente sobre el río Arga. No sabemos si la reina a que alude su nombre, fuera Doña Mayor o Doña Constanza, tuvo también que ver en la planificación urbana, pues el resultado es un plano globalmente rectangular que también comprende tres calles alargadas paralelas, seccionadas por un doble corte transversal y albergando la plaza en uno de los recodos. El mercado se hacía frente al atrio de la iglesia de San Jaime o Santiago. También el plano de Sangüesa queda determinado por el camino que lleva al puente sobre el río Aragón, convertido tal camino en calle Mayor, flanqueada por otras paralelas, y un inicio de retícula regular, algo alterado hacia el sur. Recibió el fuero de Sancho Ramírez en 1076 y medio siglo después Alfonso el Batallador trasladó la población de Sangüesa la Vieja (localizada en la colina de Rocaforte) al actual emplazamiento. Destaca, inmediata al puente, la iglesia de Santa María, exhibiendo su magnífica portada románica, ante la que pasaban los peregrinos de camino al puente.

79. Beatriz Arizaga en Guipúzcoa señala un conjunto de villas que tienden a formar un plano regular ovalado, entre las que cita como casos más típicos a Hernani, Mondragón y Villafranca de Ordizia. ARIZAGA BOLUMBURU, Beatriz, Formation et évolution du tissu urbain dans le Pays basque : l'exemple de Guipuzcoa, en : COULET, Noël, GUYOTJEANNIN, Olivier (dir. de), La Ville au Moyen Âge, Paris, ed, du CTHS, 1998. pp.41-50. Ver p.44, y la fig.2, p.45. 
clasificaciones urbanas que atiende, más que a la forma de trazado o de viario, al carácter propio de la función defensiva. Ya desde el momento en que se rodeó de murallas, estaba clara esta vocación de plaza fuerte. Pero, en la coyuntura en que fue elegida por Sancho el Sabio se le elevaba como una pieza importante de su entramado estratégico, como lo había hecho antes con Laguardia, afianzando sus fidelidades con el fuero. Era una atalaya con proyección hacia la seguridad fronteriza exterior, y como lugar de control de los caminos, pero al mismo tiempo era poner una pica en el área de los hidalgos o milites alaveses como signo inequívoco de amonestación para su acatamiento. Los muros de la colina no sólo defendían de un posible atacante, sino sobre todo diferenciaban e incluso enfrentaban dos concepciones, una tradicional, debida a la perduración de solidaridades grupales, de fidelidades familiares, pero con desigualdades en el control de las tierras y propiedades, otra novedosa, que pretendía empezar de cero y sin ataduras en la villa, acogiéndose a la protección de algunos grandes, el Rey y sus allegados.

De nuevo recordamos que el paso del siglo XII al siglo XIII resultó particularmente dramático en la joven villa de Nova Victoria: en 1199 un asedio de casi medio año, del que era testigo el arzobispo D. Rodrigo Jiménez de Rada ${ }^{80}$, con ataques y cierre de aprovisionamientos que, a principios de 1200, abocó a una rendición honrosa por hambre, no por fallo en el sistema defensivo, y con autorización de su señor natural: Sancho el Fuerte. Justo dos años más tarde, en la noche de Pascua de 1202, un fuerte incendio asolaba la villa. Como cuando se toma la decisión de quemar las naves, el incendio impulsó a nuevas alternativas, y se superó el límite de la muralla alta, surgiendo un burgo nuevo de diferente planteamiento urbano.

Nace la puebla nueva del oeste. En este momento, al menos por la estructura tan definida que nos ha llegado, sólo podemos pensar en una planificación muy organizada, con demarcaciones concretas del viario, siguiendo aproximadamente las curvas de nivel, espaciando las calles lo suficiente para albergar manzanas dobles, con caño interno de separación y desagües, recortando las vecindades con cantones, y articulando del contorno con sus cercas y puertas. Hay que reconocer la sencillez de los criterios y a la vez la eficacia

80. Los detalles de la campaña van pormenorizados en el capítulo XXXIII "De captione Victoriae, Guipuzchuae et Ibidae", del Libro VII, de la crónica De rebus Hispaniae del arzobispo navarro Don Rodrigo Jiménez de Rada, en CARO BAROJA, Julio, Alava del siglo VIII al siglo XII, I, vol III, p.51. En esta obra, conocida como "Historia gótica", sorprende el telegráfico modo en que narra la campaña, en la estela de Julio César: Rex Castellae nobilis Aldefonsus, coepit Ibidam et Alabam infestare, et obsidione diutina Victoriam impugnavit, para terminar: Obtinuit atque Rex nobilis Aldefonsus Victoriam, Ibidam Alabam et Guipuscuam. Resulta sugerente cómo alude a la intensidad del asedio: obsidione diutina Victoriam impugnavit (es decir: con un asedio prolongadísimo). 
de los resultados, que permitieron un crecimiento ocupacional armónico, incluso con densidades de habitabilidad muy altas, de manera que aún hoy es un ámbito urbano aceptable y, por ello, adaptado a la rehabilitación y no a su demolición.

La creación de esta nueva puebla se ha atribuido tradicionalmente al impulso del rey conquistador de la villa, Alfonso VIII de Castilla, aunque no sea fácil medir el alcance de su intervención personal. Sea como fuere, se demostró la eficiencia y capacidad ejecutiva. Las tres nuevas calles son, como las de Villa Suso, paralelas, pero en este caso se curvan, como marca la topografía del suelo en pendiente bajo la muralla. Su disposición en plano tiende a ser concéntrica hacia la muralla superior, igual que lo son las curvas de nivel. Eso supone que el carácter concéntrico no viene dado por una voluntad del planificador, sino por el condicionante del suelo edificable. Podemos imaginar que, en un suelo Ilano, el planificador hubiera optado por calles rectas, con un trazado ortogonal, como solución más pragmática, a la manera que se planificarán tantas bastides en Francia.

Recordaremos que, en la puebla citada hay muchos condicionantes previos: el cobijo de la muralla superior, la fuerte inclinación, en algunas zonas en torno a un $10 \%$, del terreno, el límite inferior del río Zapardiel y la cerca que lo bordea, la posibilidad de que las manzanas avancen hacia el norte, mientras se corta al sur por una línea divisoria muy firme, murada, frente a la gran explanada donde se afincará la plaza del mercado.

El trazado urbano de esta puebla se muestra ciertamente definido y regular, enmarcado en límites claros. De entre ellos, si fuera preciso, todos pueden desbordarse, menos uno que se impone desde arriba de manera contundente: la muralla alta y la acrópolis de Villa Suso. Ese elevado conjunto urbano fundacional es el macizo en torno al que se agrupa de manera parcialmente envolvente la nueva puebla. Igual que medio siglo después lo hará el siguiente desdoblamiento urbano en el lado opuesto de la colina. Este planteamiento envolvente nos parece esencial como concepto particular del trazado de este segundo proyecto urbanístico de la villa. Estas dos nuevas alas surgen como miembros adheridos al núcleo, lo engloban, lo protegen, lo complementan, y al mismo tiempo se sienten bajo su sombra. Al fin y al cabo, Villa Suso goza del prestigio de antigüedad, como una acrópolis, allí se encaraman sus mejores iglesias, vive el clero, surgirán los palacios, y es la atalaya que domina el horizonte local y los caminos que llegan de lejos.

A este respecto consideramos de gran interés una reflexión sobre los planteamientos de Pierre Lavedan, citado por Chueca Goitia: Así lo explica Pierre Lavedan. En la organización del plano se "afirman dos ideas directrices: envolvimiento y atracción: Envolvimiento por una serie de casas de un edificio particularmente precioso, sea por su valor moral, sea por su solidez material en vista de la defensa, en general, la iglesia. Atracción de la circulación por este edificio 


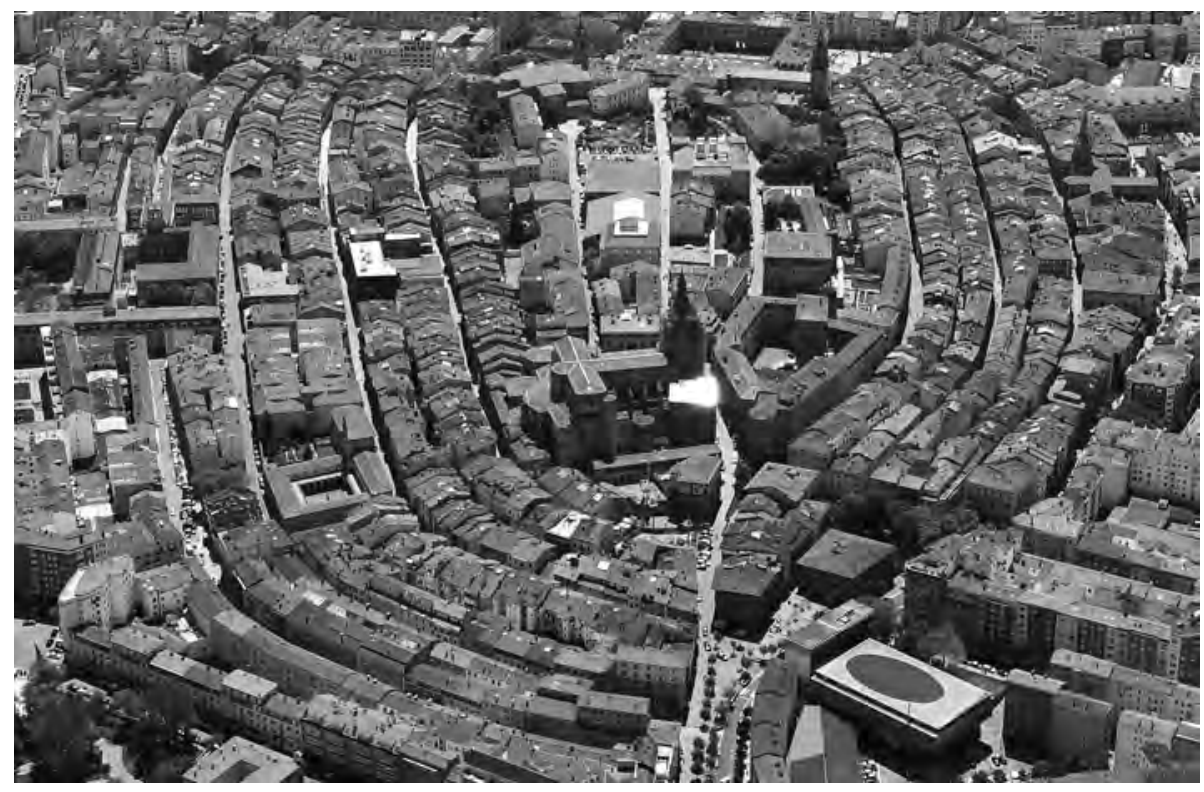

Figura 7: Vista del cierre septentrional de Villa Suso con la iglesia-fortaleza de Santa María, actual catedral. En primer plano: el remate del perímetro por un sector bajomedieval. FOAT.

y nacimiento de una serie de vías dirigidas a él. Se tiende así a un tipo de plano que los urbanistas llaman radioconcéntrico, es decir, hecho de radios y de círculos, como tela de araña» ${ }^{81}$.

A continuación, el arquitecto Chueca Goitia aplica este tipo a ejemplos concretos: El número de ciudades radioconcéntricas en el Occidente medieval es vastísimo, desde las que reflejan perfectamente el tipo a las que lo hacen de una manera más aproximada. Bram en Francia; Nordlingen, Fridnhausen y Havelberg, en Alemania; Lugignano y Aversa en Italia; Vitoria y Pamplona en España, son ejemplos sobresalientes ${ }^{82}$.

81. CHUECA GOITIA, Fernando, "Breve historia del urbanismo", Madrid, Alianza Editorial, 1980 ( $1^{\text {a }}$ ed 1968), p.98-99. Cita a LAVEDAN, Pierre, L'Architecture Française, Colls. Arts, Styles et Techniques, Paris, Larousse, 1944.

82. CHUECA GOITIA, "Breve historia...", p.99. Chueca entronca con la clasificación de Luigi Piccitano. 
Evidentemente, los ejemplos han sido muy bien seleccionados en Francia, Alemania e Italia, y parecen incontestables, pues son ciudades redondas, articuladas en red que parte de una plaza central junta a una iglesia principal, pero no nos parece que sea aplicable a Vitoria, y por ello no secundamos la idea de incluir a Vitoria en ese tipo.

Se ha solido aplicar el concepto de plano radioconcéntrico a una población cuando destaca en ella la red de calles radiales, que comunican el centro con la periferia, favoreciendo así una circulación rápida entre esos puntos. En el conjunto se aprecian también calles circunvalantes, rasgadas en ángulos muy abiertos por las radiales. Su parcelario debe adaptarse a estos quiebros o líneas diagonales, de manera que las manzanas no resultan tan regulares como en un plano ortogonal.

No es éste el caso del casco medieval de Vitoria, y por ello, a la hora de buscar una fórmula que defina los criterios seguidos en las fases de planificación, no nos parece adecuada la de plano radiconcéntrico. Falla precisamente el factor radial, pues no podemos atribuir este papel a estrechos cantones de dos metros de ancho, y, separada Villa Suso por la muralla alta, la configuración urbana general no prima, como lo muestran otros típicos ejemplos, la convergencia viaria en la plaza de la iglesia catedral.

En cambio, sí encontramos sugerente el recurrir, siguiendo a Pierre Lavedan, a la doble idea directriz de envolvimiento y atracción. Y, por ello, caracterizamos a la segunda fase de planificación de Vitoria, la de las dos pueblas laterales, como un trazado envolvente del núcleo superior. De esa manera, uniéndola con la fase primigenia de lo alto de la colina, puede refundirse la planificación medieval de Vitoria en una fórmula breve: un trazado regular -para el conjunto-, oval -para Villa Suso- y envolvente para ambas pueblas de Villa Yuso.

Al pasear por el casco antiguo de Vitoria, o al ver su plano, se percibe la sensación de una formación urbana orgánica, advirtiendo que las fases se han sucedido como las capas de una cebolla, de manera que cada nueva calle ha ido envolviendo la estructura o calle precedente. En definitiva, no nos despegamos mucho de la intuitiva y rotunda expresión de Fray Juan de Victoria: Diola forma de huevo y navío, con popa y proa ${ }^{83}$.

Para concluir, pueden ilustrarnos unos versos del que fuera Alcalde de Vitoria entre 1374 y 1375, Don Pero López de Ayala. Canciller, caballero, historiador y

83. VICTORIA, Nobiliario alavés, libro $1^{\circ}$, cap. $7^{\circ}$, f.51v ss, p. 36: Diola figura de huevo y navío, con popa y proa, hizo popa a Santa María haciéndola fortaleza con andenes almenados y muralla fuerte y andenes por de dentro para si lo bajo de la iglesia se perdiese, de las ventanas de los andenes se defendiese, como ahora se ve. Hizo también a San Vicente fortaleza de proa, y duró así, y con foso, guarnición y alcaides, hasta que los Reyes Católicos, don Fernando y doña Isabel, deshicieron el foso, torres y fuerza suya y la dejaron en pura iglesia. 
poeta, redactó entre 1385 y 1403, en momentos sombríos de prisión, su famoso y profundo Rimado de Palacio. Simplemente desgranamos la estrofa 622:

Que sean las sus villas de muro bien firmadas, Grandes torres e fuertes, altas e bien menadas, Las puertas muy fermosas e mucho bien guardadas, Que diga quien las viere que están bien ordenadas ${ }^{84}$.

84. LÓPEZ DE AYALA, Pero, Rimado de Palacio, estrofa 622, en Obra poética del Canciller Ayala, ed. a cargo de LÓPEZ YEPES, José, en “Biblioteca Luis de Ajuria”, Vitoria 1974, p.263.

* Agradecimientos: Agencia de Rehabilitación Integral de la Ciudad Histórica, Agencia Municipal de Renovación Urbana y Vivienda, y Dept $^{\circ}$ de Centro Histórico del Ayuntamiento de Vitoria-Gasteiz. 
